


\section{Sorption of pymetrozine and dimethomorph to substrate materials}

J.J.T.I. Boesten \& A.M. Matser

This research was conducted by Wageningen Environmental Research (Alterra) and funded by Nefyto and LTO Glaskracht.

Wageningen Environmental Research

Wageningen, October 2017

Report 2841

ISSN 1566-7197 
Boesten, J.J.T.I., A.M. Matser, 2017. Sorption of pymetrozine and dimethomorph to substrate materials. Wageningen, Wageningen Environmental Research, Report 2841. 48 pp.; 10 fig.; 12 tab.; 7 ref.

Sorption of pesticides to solid materials used in soilless stonewool cultures is relevant because it may reduce emissions to surface water. The sorption of pymetrozine and dimethomorph was studied in batch experiments with clean stonewool, drip-irrigation pipes, transport pipes and the plastic foil surrounding the stonewool. The sorption coefficient of stonewool was found to be $0.2 \mathrm{~L} / \mathrm{kg}$ for pymetrozine and $1.0 \mathrm{~L} / \mathrm{kg}$ for the two isomers of dimethomorph. Sorption of pymetrozine to the pipes and the foil was negligibly small. The sorption coefficients of the two isomers of dimethomorph were $0.07-0.12 \mathrm{~L} / \mathrm{kg}$ for the transport pipes, $0.14-0.16 \mathrm{~L} / \mathrm{kg}$ for the drip-irrigation pipes and $1.2-1.5 \mathrm{~L} / \mathrm{kg}$ for the foil. Studies were performed in which an aqueous solution of the pesticides was circulated through stonewool mats containing an intact sweet-pepper plant (triplicate plant systems) sampled at the end of the growing cycle. Pymetrozine did not show any interaction with the solid phases in these circulation studies. Dimethomorph showed a concentration decrease that was $10 \%$ higher than expected from the batch studies with clean stonewool. An exploratory calculation showed that this $10 \%$ may be the result of partitioning into the roots and that this may correspond to $30 \%$ decrease in a stonewool growing system in the greenhouse. It is recommended to incorporate (i) sorption to stonewool and drip-irrigation pipes and (ii) partitioning into the roots into the GEM model and to assess the sensitivity of the emission concentrations to these processes for substances like dimethomorph.

Keywords: plant protection products, pesticides, soilless culture, stonewool

The pdf file is free of charge and can be downloaded at https://doi.org/10.18174/425040 or via the website www.wur.nl/environmental-research (scroll down to Publications - Wageningen Environmental Research reports). Wageningen Environmental Research does not deliver printed versions of the Wageningen Environmental Research reports.

2017 Wageningen Environmental Research (an institute under the auspices of the Stichting Wageningen Research), P.O. Box 47,6700 AA Wageningen, The Netherlands, T +31 (0)317 4807 00, E info.alterra@wur.nl, www.wur.nl/environmental-research. Wageningen Environmental Research is part of Wageningen University \& Research.

- Acquisition, duplication and transmission of this publication is permitted with clear acknowledgement of the source.

- Acquisition, duplication and transmission is not permitted for commercial purposes and/or monetary gain.

- Acquisition, duplication and transmission is not permitted of any parts of this publication for which the copyrights clearly rest with other parties and/or are reserved.

Wageningen Environmental Research assumes no liability for any losses resulting from the use of the research results or recommendations in this report.

Wageningen Environmental Research Report 2841 | ISSN 1566-7197

Photo cover: Arrienne Matser (stonewool batch sorption system) 


\section{Contents}

$\begin{array}{ll}\text { Preface } & 5\end{array}$

$\begin{array}{ll}\text { Summary } & 7\end{array}$

1

$\begin{array}{ll}\text { Introduction } & 9\end{array}$

Batch sorption studies with stonewool, pipe materials and stonewool foil $\quad 10$

2.1 Materials and methods $\quad 10$

2.1.1 Procedures of batch sorption studies with clean stonewool 10

2.1.2 Procedures of batch sorption studies with pipe materials and stonewool foil

2.1.3 Analysis of pymetrozine and dimethomorph in water, acetone and methanol samples 13

2.2 Results 14

2.2.1 Batch sorption studies with clean stonewool $\quad 14$

2.2.2 Batch sorption studies with pipe materials and stonewool foil 16

3.1 Materials and methods $\quad 19$

3.1.1 Introduction 19

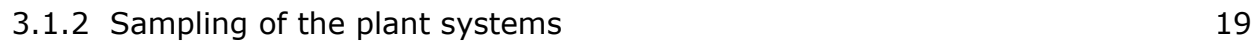

3.1.3 Procedures of the laboratory experiments 20

$\begin{array}{lll}3.2 & \text { Results } & 22\end{array}$

$\begin{array}{llr}4 & \text { Discussion and conclusions } & 28\end{array}$

$4.1 \quad$ Batch sorption studies $\quad 28$

4.2 Circulation studies $\quad 29$

$\begin{array}{ll}\text { References } & 31\end{array}$

Annex $1 \quad$ Details of analytical procedures $\quad 32$

Annex 2 Detailed results of batch sorption experiments with clean stonewool

41

Annex 3 Detailed results of batch sorption experiments with pipe materials and stonewool foil

Annex 4 Schematic representation of the circulation systems of the mats with the plants 



\section{Preface}

We thank Nefyto and LTO Glaskracht for their financial support to conduct these sorption studies which enable to assess the significance of the sorption to substrate materials for the emission of plant protection products to Dutch surface water from soilless stonewool cultures in greenhouses. This project was established within the framework of the innovation programme 'Het Nieuwe Doen in Plantgezondheid Glastuinbouw' of LTO Glaskracht Nederland and partly financed by the Stichting Programmafonds Glastuinbouw (project nr P16006).

We thank furthermore Ton van der Linden (RIVM) and our colleague Louise Wipfler for useful comments that helped to improve this report. 


\section{Summary}

It is a point of discussion whether sorption of plant protection products to substrate materials should be included in the GEM model which is currently used to assess the emission of PPPs to surface water from soilless cultures in Dutch greenhouses. Only very little data on this sorption are available in literature. Therefore the sorption of two pesticides (pymetrozine and dimethomorph) to substrate materials was studied in batch and circulation experiments. The batch experiments were carried out with clean stonewool and plastic materials used in the growing system. The circulation experiments were carried out using a piece of mat of about $30 \mathrm{~cm}$ long with in the centre an intact sweet-pepper plant (cut at approximately $50 \mathrm{~cm}$ height), taken from the greenhouse at the end of the sweet-pepper growing cycle. The argument for using the stonewool mats at the end of the growing cycle was that these will generate the highest sorption because of the increase in the organic-matter material in the mat during the growing cycle.

Batch adsorption experiments were conducted with stonewool from two manufacturers (Cultilene and Grotop) at a solid-liquid ratio of about $0.05 \mathrm{~kg} / \mathrm{L}$ using an aqueous solution with a calcium nitrate concentration of $0.02 \mathrm{~mol} / \mathrm{L}$. The equilibration time was $1 \mathrm{~h}$ and the initial concentration of either pymetrozine or dimethomorph was about 0.07-0.08 $\mathrm{mg} / \mathrm{L}$. Two methods for measuring the sorption were used in parallel; the first is based on the decrease of the initial concentration and the second on an extraction with methanol at the end of the experiment. The extraction method was found to be the most reliable. Differences between the two types of stonewool and between the two isomers of dimethomorph were found to be insignificant. The resulting linear sorption coefficient of pymetrozine was estimated to be $0.2 \mathrm{~L} / \mathrm{kg}$ and that of the isomers of dimethomorph was estimated to be $1.0 \mathrm{~L} / \mathrm{kg}$. In literature, stonewool sorption coefficients of two other pesticides were found and ranking of the four sorption coefficients based on the octanol-water coefficient of the pesticide showed a continuous increase of the sorption coefficient with increasing octanol-water coefficient.

Batch adsorption experiments were conducted with plastic materials that are used in the stonewool growing system: materials from drip-irrigation pipes, transport pipes and the foil surrounding the stonewool. Solid-liquid ratios ranged between 0.2 and $0.5 \mathrm{~kg} / \mathrm{L}$ using an aqueous solution with a calcium nitrate concentration of $0.02 \mathrm{~mol} / \mathrm{L}$. The equilibration time was $1 \mathrm{~h}$; the initial concentration of pymetrozine was about $0.1 \mathrm{mg} / \mathrm{L}$ and that of dimethomorph was $0.08-0.09 \mathrm{mg} / \mathrm{L}$ (the aqueous solution contained both substances). The same two methods for measuring the sorption were used as for the stonewool. For pymetrozine no sorption could be measured. For the isomers of dimethomorph, the extraction method was found to be more reliable for the drip-irrigation and the transport pipes and the concentration-decrease method was found to be more reliable for the stonewool foil. The sorption coefficients for the transport pipes were found to be 0.07 and $0.12 \mathrm{~L} / \mathrm{kg}$ for the $\mathrm{E}$ - and the Z-isomer, respectively. The sorption coefficients for the drip-irrigation pipes were found to be 0.14 and $0.16 \mathrm{~L} / \mathrm{kg}$ for the E- and the Z-isomer, respectively. The sorption coefficients for the stonewool foil were found to be 1.5 and $1.2 \mathrm{~L} / \mathrm{kg}$ for the $\mathrm{E}$ - and the $\mathrm{Z}$-isomer, respectively. In these batch experiments the sorption to both the inner and the outer side of the materials is measured whereas the pesticides are in contact with only the inner side of the materials in the growing system, so it is recommended to halve the above sorption coefficients when used in GEM for exposure modelling.

An exploratory calculation showed that the combination of the sorption coefficients of the stonewool and the drip irrigation pipes might lead to a concentration decrease close to $20 \%$ for dimethomorph. It is therefore recommended to include sorption to stonewool and the drip irrigation pipes in GEM and to assess the effect of these processes on the emission concentrations.

Circulation studies were conducted with pieces of mats (30 cm long) with a plant in the centre of each mat (in triplicate). The procedure was to circulate a solution containing the pesticides through the system for approximately $6 \mathrm{~h}$ and to measure the course of time of the pesticide concentration and compare it to the concentration to be expected if no sorption takes place. The circulation solution 
contained both pymetrozine and dimethomorph. The concentration of pymetrozine was about $3 \mathrm{mg} / \mathrm{L}$ and that of dimethomorph was about $0.8 \mathrm{mg} / \mathrm{L}$ (assuming complete mixing of all the water and no sorption). Besides the studies with the triplicate plant systems, also a circulation study was carried out without any sorbing material (so a blank system) plus a circulation study with a piece of clean stonewool mat. In none of the experiments a concentration decrease of pymetrozine was observed so this showed no interaction with the solid phases in the system. The study with the blank system indicated a significant amount of sorption of dimethomorph to the plastic tubing material used in the circulation system (this material was different from the plastic materials studied in the batch experiments). Therefore at the end of the experiments with the plant systems and the clean stonewool mat the plastic tubes were flushed with acetone or methanol with the aim to correct for the masses of dimethomorph sorbed to the plastic tubes. This flushing resulted in recovery of $8-12 \%$ of the added mass of dimethomorph. Further interpretation of the experiments with the blank system and the clean stonewool mat indicated that probably an additional $10 \%$ of the added mass of dimethomorph was sorbed to the plastic tubes. After correcting for also this additional $10 \%$, it was concluded that the circulation studies resulted in a dimethomorph concentration that was $10 \%$ lower than expected from the batch adsorption experiments with the clean stonewool. Exploratory calculations showed that these $10 \%$ may have been the result of partitioning of dimethomorph into the roots and that $10 \%$ decrease in this circulation system may correspond with about 30\% decrease in the stonewool system in the greenhouse. It is therefore recommended to include this partitioning into the roots in the GEM model and to assess the sensitivity of the emission concentrations to this process. 


\section{Introduction}

The Greenhouse Emission Model (GEM) is used in the Dutch pesticide registration procedure to assess emission of plant protection products (PPPs) from soilless growing systems (including stonewool substrate) to surface water. This model does not consider sorption of PPPs to the substrate and other materials in the substrate system because of lack of such sorption data.

Emission of PPPs from soilless growing systems into the surface water is an important aspect of the environmental risk assessment of these PPPs. Thus, it is desirable that the description of the behaviour of PPPs in the GEM model for these growing systems is as realistic as possible. An experiment from 2014 on the behaviour of three PPPs in a stonewool substrate system showed differences between the time of breakthrough of the substances in the drainage water (sequence from fast to slow was imidacloprid-fluopyram-dimethomorph). These differences were probably the result of differences in sorption to the substrate materials. The current version of the GEM model cannot describe such differences because it does not consider this sorption. Furthermore in June 2016 an experiment was conducted in a sweet-pepper/stonewool substrate system with imidacloprid and pymetrozine (results not yet available). In view of its properties, sorption of pymetrozine is expected to be larger than that of imidacloprid (Table 1). Thus, sorption measurements with dimethomorph and pymetrozine were considered relevant.

Table 1 Physicochemical properties of dimethomorph, imidacloprid and pymetrozine (dimethomorph from EFSA, 2006, and imidacloprid and pymetrozine from PPDB database at http://sitem.herts.ac.uk/aeru/iupac).

\begin{tabular}{|c|c|c|c|c|}
\hline \multirow[t]{2}{*}{ property } & \multicolumn{2}{|c|}{ dimethomorph } & \multirow[t]{2}{*}{ imidacloprid } & \multirow[t]{2}{*}{ pymetrozine } \\
\hline & E-isomer & Z-isomer & & \\
\hline water solubility (mg/L) & 47 & 11 & 610 & 270 \\
\hline $\log \mathrm{K}_{\mathrm{ow}}$ & 2.6 & 2.7 & 0.6 & -0.2 \\
\hline $\mathrm{K}_{\mathrm{oc}}(\mathrm{L} / \mathrm{kg})$ & $300-600$ & $300-500$ & 200 & 1000 \\
\hline
\end{tabular}

The project aimed to generate experimental data on the sorption of pymetrozine and dimethomorph to substrate materials with the expectation that these data will indicated the need to include the sorption of PPPs to substrate materials in the GEM model.

Sorption experiments were conducted with the following sorbing materials:

\# clean/fresh stonewool (as delivered by the manufacturer)

\# pieces of stonewool mats collected at the end of the sweet-pepper growing cycle (early November)

\# pipe materials that are used in the sweet-pepper growing system

\# the foil around the stonewool.

The argument for using both clean stonewool as the stonewool mats at the end of the growing cycle was that these will generate the extremes with respect to sorption (clean stonewool lowest sorption and mats at end of growing cycle highest sorption). The sorption to the clean stonewool, the pipe materials and the foil was measured in batch experiments, whereas the sorption to the stonewool mats was studied in a circulation study to keep the root material under realistic conditions.

Chapter 2 describes the studies with the clean stonewool, the pipe materials and the stonewool foil and chapter 3 describes the studies with the stonewool mats collected at the end of the growing cycle. 


\section{Batch sorption studies with stonewool, pipe materials and stonewool foil}

\subsection{Materials and methods}

\subsubsection{Procedures of batch sorption studies with clean stonewool}

The aim of the batch experiments was to measure sorption of pymetrozine and dimethomorph to clean stonewool in a system where there is perfect mixing of the water. The principle of the measurement procedure is to add an aqueous pesticide solution to the stonewool and to measure the decrease in the pesticide concentration caused by the sorption. However, it was expected that the sorption of pymetrozine and dimethomorph to the stonewool is low. Thus the decrease was expected to be small and the accuracy of the sorption measurement was expected to be low. Therefore an alternative measurement procedure was applied in parallel. In this procedure the solution is removed from the stonewool as much as possible after the sorption equilibration and the stonewool plus remaining solution is extracted with organic solvent. This is expected to give a more accurate result (Boesten, 1990).

Experiments were conducted with stonewool from two manufacturers (Cultilene and Grotop). Stonewool mats were placed in buckets and pre-equilibrated for $1 \mathrm{~h}$ and $15 \mathrm{~min}$ in a solution of distilled water containing $0.02 \mathrm{~mol} / \mathrm{L} \mathrm{Ca}\left(\mathrm{NO}_{3}\right)_{2}$ (further called ' $\mathrm{Ca}\left(\mathrm{NO}_{3}\right)_{2}$ solution'). This preequilibration was done because fresh stonewool is expected to increase the $\mathrm{pH}$ of the solution (Matser \& Leistra, 1997) because it is made of limestone for $20 \%$. The upper limit of the $\mathrm{pH}$ in standard water for substrate cultures is 6 (van Ruiven et al. 2016) so it was the intention that this pre-equilibration resulted in lowering of the $\mathrm{pH}$ to 6 . The buckets were not closed so in contact with air. The $\mathrm{pH}$ of the $\mathrm{Ca}\left(\mathrm{NO}_{3}\right)_{2}$ solution had decreased to below 6 after this pre-equilibration. Some ten pieces of moist stonewool (in total 3-4 g of dry stonewool) were put into a glass centrifuge tube (four replicates for Cultilene and four replicates for Grotop). About $60 \mathrm{~mL}$ of pesticide-free $\mathrm{Ca}\left(\mathrm{NO}_{3}\right)_{2}$ solution was added, the tubes were closed with a stopper and were rotated on a wheel (Figure 1 ) for $1 \mathrm{~h}$ at a rotation frequency of $6 \mathrm{~min}^{-1}$.

The $\mathrm{pH}$ of the solution was measured and ranged between 6.0 and 6.6 (except one tube which had a $\mathrm{pH}$ of 5.5). Probably the closer contact between stonewool and solution caused by rotating the tubes led to an increase of the $\mathrm{pH}$. The solution was decanted which left about $20 \mathrm{~mL}$ of $\mathrm{Ca}\left(\mathrm{NO}_{3}\right)_{2}$ solution in the tubes. To three of the four replicates $0.1 \mathrm{~mL}$ of a buffer $(\mathrm{pH}=4$ based on potassium hydrogen phthalate) was added; this was not added to the fourth replicate to be able to detect a possible effect of adding the buffer.

A volume of about $50 \mathrm{~mL}$ of $\mathrm{Ca}\left(\mathrm{NO}_{3}\right)_{2}$ solution containing either pymetrozine or dimethomorph at a concentration of about $0.1 \mathrm{mg} / \mathrm{L}$ was added. The concentrations in this solution were measured. Both for pymetrozine and dimethomorph two centrifuge tubes were added which contained only the pesticide solutions (so without stonewool). All tubes were rotated on the wheel (Figure 1 ) for $1 \mathrm{~h}$ at a rotation frequency of $6 \mathrm{~min}^{-1}$ and at a room temperature of about $20^{\circ} \mathrm{C}$.

It was the intention to use a solid-liquid ratio (i.e. mass of dry stonewool divided by volume of $\mathrm{Ca}\left(\mathrm{NO}_{3}\right)_{2}$ solution) that was as high as possible because the measurement error of sorption coefficients decreases with increasing solid-liquid ratio (Boesten, 1990). However, some $70 \mathrm{~mL}$ of $\mathrm{Ca}\left(\mathrm{NO}_{3}\right)_{2}$ solution appeared to be needed to ensure a good mixing of the liquid phased during the rotation. Thus the experiments were carried out at a solid-liquid ratio of about $0.05 \mathrm{~g} / \mathrm{mL}$ (which is very low compared to sorption studies with soil where ratios of about $1 \mathrm{~g} / \mathrm{mL}$ can be used). 

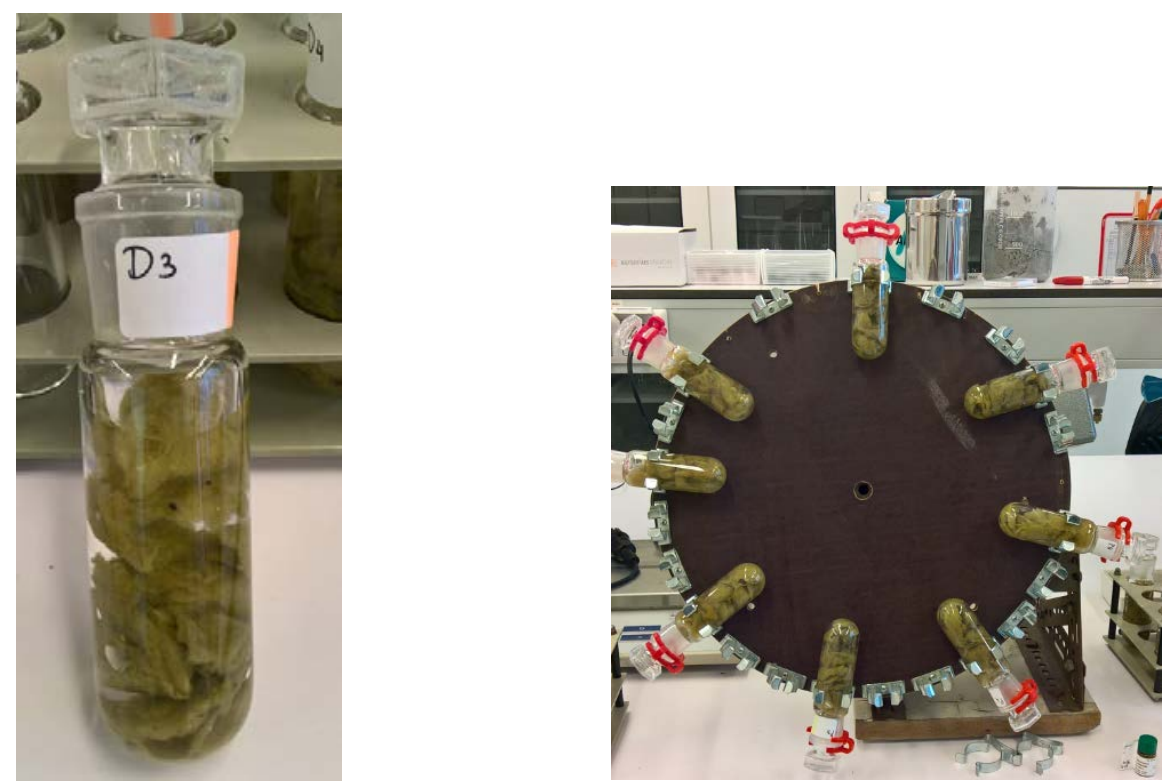

Figure 1 Photographs of one of the batch stonewool systems and of the rotation wheel used for equilibration.

After the 1-h rotation with pesticide solution, the tubes were centrifuged and a sample of the supernatant was taken for pesticide analysis. Then the $\mathrm{pH}$ of the supernatant of each tube that contained stonewool was measured. In the experiment with pymetrozine, the $\mathrm{pH}$ of the tubes with the buffer ranged from 5.6 to 5.7 for the Grotop and was 5.9 for Cultilene. The tube without buffer had a $\mathrm{pH}$ of 5.9 (Grotop) and 6.0 (Cultilene). In the experiment with dimethomorph the pH of the tubes with the buffer ranged from 5.8 to 5.9 for the Grotop and from 6.0-6.1 for Cultilene. The tube without buffer had a pH of 6.0 (Grotop) and 6.1 (Cultilene).

After the measurement of the $\mathrm{pH}$ as much solution as possible was removed. In the experiment with pymetrozine, this left 22-25 g solution in the system for Grotop and $18-22 \mathrm{~g}$ for Cultilene. In the experiment with dimethomorph, this left 17-20 g solution in the system for Grotop and $18-21 \mathrm{~g}$ for Cultilene. Methanol (a volume of about $36 \mathrm{~mL}$ for pymetrozine and about $50 \mathrm{~mL}$ for dimethomorph) was added to each tube and the tubes were shaken horizontally for $1 \mathrm{~h}$ at 175 movements per minute. After settling of the batch system a sample of the supernatant was taken for pesticide analysis.

At the end of each experiment, the tubes were dried at $105^{\circ} \mathrm{C}$ overnight to measure the mass of dry stonewool added to each tube.

Masses of the tubes were measured in all steps so the volume of the liquid phase just before adding the pesticide solutions could be calculated. This volume was used to calculate the initial concentration of the pesticides in the system. Thus also the volume of liquid phase just before adding the methanol could be calculated. The mass sorbed onto the solid phase was calculated from the difference between the mass extracted with methanol and the mass present in the liquid phase just before adding the methanol. From the mass extracted with methanol plus the mass in the removed supernatant solution also the recovery of the added mass of pesticide could be calculated.

The results of the sorption measurements were described in terms of the measured sorption coefficient assuming a linear sorption isotherm:

$X=K c$

where $X$ is the mass of pesticide sorbed per mass of solid phase $(\mathrm{mg} / \mathrm{kg}), c$ is the concentration in the liquid phase $(\mathrm{mg} / \mathrm{L})$ and $K$ is the linear sorption coefficient $(\mathrm{L} / \mathrm{kg})$. 


\subsubsection{Procedures of batch sorption studies with pipe materials and stonewool foil}

The aim of the batch experiments was to measure sorption of pymetrozine and dimethomorph to pipe materials and stonewool foil. Also here low sorption was expected so both the decrease in the liquid phase was measured and the materials were extracted with methanol after the sorption equilibration.

Experiments were conducted with two pipe materials, i.e. drip-irrigation pipes (further abbreviated to ' $D P^{\prime}$ ) and transport pipes (further abbreviated to 'TP') and stonewool foil from Cultilene stonewool (further abbreviated to 'SF'). The transport pipes consisted of 2-mm thick PVC and had an outer diameter of $32 \mathrm{~mm}$. These were cut in pieces that ranged in size between $5 \times 5 \mathrm{~mm}$ and $10 \times 10 \mathrm{~mm}$ (Figure 2).

The drip-irrigation pipes consisted of a black inner ring and a white outer ring. The outer diameter of the pipes was about $5 \mathrm{~mm}$ and the inner diameter about $4 \mathrm{~mm}$. The pipes were cut in pieces of 2-4 mm (Figure 2). The foil consisted of PVC and was cut in pieces ranging in size between $5 \times 5 \mathrm{~mm}$ and $10 \times 10 \mathrm{~mm}$ (Figure 2).

The masses and two-sided surface areas of samples of these materials were measured and the surface area per mass was found to be 8,21 and $281 \mathrm{~cm}^{2} / \mathrm{g}$ for the TP, DP and SF materials, respectively (the cutting faces were not included in this measurement). The mass of the pipe materials per length of the pipe was $2.38 \mathrm{~g} / \mathrm{cm}$ for TP and $0.147 \mathrm{~g} / \mathrm{cm}$ for DP.

For the interpretation of the sorption coefficients of TP and DP it is meaningful to calculate the ratio between the mass of the pipe and the volume of liquid contained in it. Let us first consider $1 \mathrm{~cm}$ of drip-irrigation pipe; this had an inner diameter of about $4 \mathrm{~mm}$, so an inner surface area of $12.6 \mathrm{~mm}^{2}$ $=0.126 \mathrm{~cm}^{2}$ so the volume of liquid in $1 \mathrm{~cm}$ of pipe is $0.126 \mathrm{~cm}^{3}$ whereas the mass of $1 \mathrm{~cm}$ of pipe is $0.147 \mathrm{~g}$ : this gives a mass/volume ratio of $1.2 \mathrm{~g} / \mathrm{cm}^{3}=1.2 \mathrm{~kg} / \mathrm{L}$ for DP. The transport pipes had an inner diameter of $30 \mathrm{~mm}$ so an inner surface area of $7.07 \mathrm{~cm}^{2}$, so the volume of liquid in $1 \mathrm{~cm}$ of pipe is $7.07 \mathrm{~cm}^{3}$ whereas $1 \mathrm{~cm}$ of pipe has a mass of $2.38 \mathrm{~g}$; this gives a mass volume ratio of $0.34 \mathrm{~g} / \mathrm{cm}^{3}$ $=0.34 \mathrm{~kg} / \mathrm{L}$ for TP.

For the interpretation of the sorption coefficients of SF it is meaningful to calculate the ratio between the mass of foil and the volume of liquid in the mat that is in contact with the foil. The height of a sample of Cultilene stonewool was $7.2 \mathrm{~cm}$ and its width was $11.8 \mathrm{~cm}$; this gives a perimeter of the stonewool of $38 \mathrm{~cm}$. The length of the surrounding piece of foil was $38.6 \mathrm{~cm}$, so slightly wider. Let us consider a stonewool slice of $1 \mathrm{~cm}$. This has a volume of $11.8 \times 7.2=85 \mathrm{~cm}^{3}$. The volume fraction of water in a mat is typically 0.6 (van der Maas et al., 2015) so this gives about $50 \mathrm{~cm}^{3}$ of liquid. The surface area of $1 \mathrm{~cm}$ of surrounding foil is $38.6 \mathrm{~cm}^{2}$. This corresponds with a mass of 38.6/281 $=0.14 \mathrm{~g}$. So the mass volume ratio is $0.14 \mathrm{~g} / 50 \mathrm{~cm}^{3}=0.03 \mathrm{~g} / \mathrm{cm}^{3}=0.03 \mathrm{~kg} / \mathrm{L}$. The properties of the sorption materials are summarized in Table 2.

Table 2 Properties of the pipe materials and the stonewool foil. The mass per volume of liquid is estimated assuming that the pipes are $100 \%$ filled with water and that the volume fraction of liquid in the stonewool mat is $60 \%$.

\begin{tabular}{lccc} 
& & DP & \\
surface area per mass $\left(\mathrm{cm}^{2} / \mathrm{g}\right)$ & 8 & 21 & 281 \\
\hline mass per length of pipe $(\mathrm{g} / \mathrm{cm})$ & 2.4 & 0.15 & \\
\hline mass per volume of liquid $(\mathrm{kg} / \mathrm{L})$ & 0.34 & 1.2 & 0.03 \\
\hline
\end{tabular}

All experiments were conducted in $10-\mathrm{mL}$ centrifuge tubes with about $5 \mathrm{~mL}$ of $\mathrm{Ca}\left(\mathrm{NO}_{3}\right)_{2}$ solution $(0.02 \mathrm{~mol} / \mathrm{L})$ for the TP material. The solid phase was $2.6-2.7 \mathrm{~g}$ of TP material, $2.0 \mathrm{~g}$ of DP material, or $1.0-1.1 \mathrm{~g}$ of SF material. The mass of solid phase in each tube was measured with an accuracy of $0.01 \mathrm{~g}$. The solution contained pymetrozine at a concentration of about $100 \mu \mathrm{g} / \mathrm{L}, \mathrm{E}$-dimethomorph at a concentration of about 30-40 $\mu \mathrm{g} / \mathrm{L}$ and Z-dimethomorph at a concentration of about $50 \mu \mathrm{g} / \mathrm{L}$. All tubes were rotated on a wheel for $1 \mathrm{~h}$ at a rotation frequency of $6 \mathrm{~min}^{-1}$ and at a room temperature of about $20^{\circ} \mathrm{C}$. 

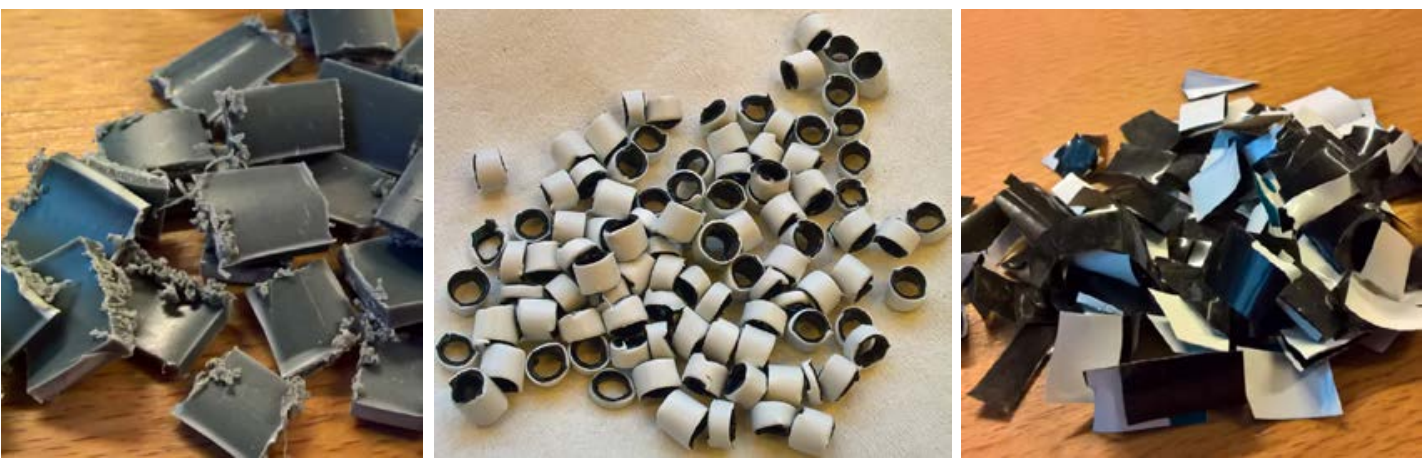

Figure 2 Photographs of the batch pipe materials: transport pipe (TP) left, drip irrigation pipes (DP) middle, and stonewool foil (SF) right.

A sample of the supernatant was taken for pesticide analysis. The tubes were centrifuged and as much solution as possible was removed. This left 0.4-0.5 g solution in the system for the TP material, 0.5-0.7 $\mathrm{g}$ for the DP material and $1-2 \mathrm{~g}$ for the SF material. Methanol $(4 \mathrm{~g}$ for the TP and DP material and $6 \mathrm{~g}$ for the SF material) was added to each tube and the tubes were shaken horizontally for $1 \mathrm{~h}$ at 200 movements per minute. Then a sample of the supernatant was taken for pesticide analysis. The mass of pesticide sorbed was calculated using the same procedure as described in the previous section.

\subsubsection{Analysis of pymetrozine and dimethomorph in water, acetone and methanol samples}

The LC-MS/MS method for pymetrozine and dimethomorph analysis was developed at the laboratory of Wageningen Environmental Research. See Annex 1 for details of the analytical procedure and a number of example chromatograms. Table 3 describes the reagents and solvents that were used.

\section{Table $3 \quad$ Overview of reagents and solvents}

\begin{tabular}{|c|c|c|}
\hline Reagent/ solvent & Purity & Source \\
\hline Water & & prepared by Advantage A10 Milli-Q water system \\
\hline Methanol & $100 \%$ & $\begin{array}{l}\text { HiPerSolv Chromanorm, VWR PROLABO, gradient grade, art.nr. } \\
20864.420\end{array}$ \\
\hline Acetone & $100 \%$ & HiPerSolv Chromanorm, VWR, art.nr. 20067.320 \\
\hline Ammonium acetate & & 5M Ammonium acetate solution in water, Fluka, product code 101310728 \\
\hline Analytical standard pymetrozine & $99.0 \%$ & dr. Ehrenstorfer, product identification C16587000 \\
\hline $\begin{array}{l}\text { Analytical standard } \\
\text { dimethomorph (mixture of } E \text { and } \\
Z \text { isomer) }\end{array}$ & $98.0 \%$ & dr. Ehrenstorfer, product identification C12710000 \\
\hline
\end{tabular}

Calibration standards were prepared using analytical standards received from dr. Ehrenstorfer, with purities of $99.0 \%$ and $98.0 \%$ for pymetrozine and dimethomorph.

A stock calibration standard of pymetrozine was prepared by dissolving $0.0106 \mathrm{~g}$ of the reference material in $79.0141 \mathrm{~g}$ methanol (density of $0.791 \mathrm{~g} / \mathrm{mL}$ ) to a final concentration of $105.05 \mu \mathrm{g} / \mathrm{mL}$ pymetrozine. This stock calibration standard was stored in the freezer at a temperature below $-10{ }^{\circ} \mathrm{C}$.

A stock calibration standard of dimethomorph was prepared by dissolving $0.0126 \mathrm{~g}$ of the reference material in $48.8965 \mathrm{~g}$ methanol (density of $0.791 \mathrm{~g} / \mathrm{mL}$ ) to an end concentration of $199.75 \mu \mathrm{g} / \mathrm{mL}$ 
dimethomorph (mixture of $E$ and $Z$ isomer). This stock solution was stored in the freezer at temperature below $-10{ }^{\circ} \mathrm{C}$.

A stock calibration standard of a mixture of pymetrozine and dimethomorph was prepared by weighing $7.964 \mathrm{~g}$ pymetrozine in methanol with a concentration of $105.05 \mu \mathrm{g} / \mathrm{mL}$ and $3.955 \mathrm{~g}$ dimethomorph in methanol with a concentration of $199.75 \mu \mathrm{g} / \mathrm{mL}$ in a flask and fill-up to $100 \mathrm{~mL}$ with a mixture of methanol and Milli-Q water (15/85 by volume). The concentration pymetrozine and dimethomorph in de mix standard is resp. $9.9875 \mu \mathrm{g} / \mathrm{mL}$ and $10.5767 \mu \mathrm{g} / \mathrm{mL}$. This stock solution was stored in the refrigerator. This solution is further called the 'mix standard'.

The calibration standards used for measuring the concentration in the samples were prepared from the mix standard by using a dilutor Hamilton 600 . The mix standard was diluted with a mixture of methanol and Milli-Q water containing $0.02 \mathrm{~mol} / \mathrm{L} \mathrm{Ca}\left(\mathrm{NO}_{3}\right)_{2}$; the volume ratio of methanol and the water was $15 / 85$. The concentration levels of the calibration standards were: 1000-500-250-100-5025-10 ng/mL.

Water samples were taken in duplo with a glass pipette and approximately $3 \mathrm{~mL}$ of sample was added to a 4-mL glass vial containing $0.6 \mathrm{~mL}$ methanol. After homogenizing by vortex a sub-sample was taken from one of the duplicate samples and transferred to a 2-mL vial for LC-MS/MS analysis. If the concentration was expected to be too high, the sample was diluted with the mixture of methanol and Milli-Q water containing $0.02 \mathrm{~mol} / \mathrm{L} \mathrm{Ca}\left(\mathrm{NO}_{3}\right)_{2}$ by using the dilutor. Samples were stored in the refrigerator.

Subsamples of the methanol samples were evaporated to dryness and the substances were dissolved in $0.3 \mathrm{~mL}$ of methanol using ultrasonic vibration. The same procedure was used for the acetone samples (see Section 3.1.3). A volume of $1.7 \mathrm{~mL}$ of Milli-Q water containing $0.02 \mathrm{~mol} / \mathrm{L} \mathrm{Ca}\left(\mathrm{NO}_{3}\right)_{2}$ was added and the mixture was analysed by LC-MS/MS.

\section{$2.2 \quad$ Results}

\subsubsection{Batch sorption studies with clean stonewool}

Table 4 shows that all concentrations for pymetrozine in the tubes without stonewool were at the end of the experiment very close to the average concentration of pymetrozine added $(109 \mu \mathrm{g} / \mathrm{L})$. Somewhat surprisingly the concentrations of E-dimethomorph increased some $10 \%$ wherease the concentrations of Z-dimethomorph were close to the concentrations added. Thus the $10 \%$ increase for E-dimethomorph is possibly the result of an analytical artefact.

Table 4 Pesticide concentrations in the solution added to tubes without solid materials and pesticide concentrations in these tubes at the end of experiment with the stonewool. All concentrations are expressed as percentages of the average initial concentrations (i.e. $109 \mu \mathrm{g} / \mathrm{L} \mathrm{pymetrozine,} 28 \mu \mathrm{g} / \mathrm{L}$ E-dimethomorph, $72 \mu \mathrm{g} / \mathrm{L} Z$-dimethomorph, and $100 \mu \mathrm{g} / \mathrm{L}$ for the sum of the $E$ and $Z$ isomers).

\begin{tabular}{|c|c|c|c|c|c|}
\hline & & \multirow[t]{2}{*}{ pymetrozine } & \multicolumn{3}{|c|}{ dimethomorph } \\
\hline & & & E-isomer & Z-isomer & sum \\
\hline $\begin{array}{l}\text { concentrations in duplicate samples of } \\
\text { solution added (\%) }\end{array}$ & $\mathrm{nr} 1$ & 100 & 100 & 104 & 103 \\
\hline \multirow{2}{*}{$\begin{array}{l}\text { concentrations in duplicate systems without } \\
\text { stonewool at end of experiment (\%) }\end{array}$} & $\mathrm{nr} 1$ & 100 & 110 & 99 & 102 \\
\hline & $\mathrm{nr} 2$ & 101 & 109 & 100 & 103 \\
\hline
\end{tabular}

As described in Section 2.1.1, two methods were applied for the measurement of the sorption of the pesticides onto the clean stonewool: (1) based on the decrease in the concentration in the liquid phase before and after sorption equilibration, and (2) based on the mass of pesticide extracted from the solid phase with methanol at the end of the experiment. 
Detailed results of all sorption measurements with clean stonewool are given in Annex 2. A summary of these results in Table 5 show that the methanol extraction generated more consistent results than the concentration decrease. The recovery (based on the methanol extraction) was very close to $100 \%$ for pymetrozine, somewhat above $100 \%$ for E-dimethomorph and somewhat below $100 \%$ for Z-dimethomorph. It is a possibility that part of the Z-isomer was converted into the E-isomer during the sorption equilibration. This would explain the large difference between the sorption coefficients of the $Z$ and $E$ isomers derived from the decrease in the concentrations. The measurement based on the methanol extraction is less sensitive to conversion between the isomers because both the mass sorbed and the concentration in the liquid phase are measured at the end of the equilibration.

Figure 3 contains only the numbers based on the methanol extraction because these were considered more reliable (as described in previous paragraph). The figure shows that differences between the Z- and E-isomers are not significant and that also differences between Grotop and Cultilene were not significant. Thus the best estimate of the sorption coefficient of pymetrozine to clean stonewool is $0.2 \mathrm{~L} / \mathrm{kg}$ and that of the two isomers of dimethomorph is $1.0 \mathrm{~L} / \mathrm{kg}$.

To assess the significance of these sorption coefficients, we consider the percentage sorbed in a system with a mass of solid phase $M(\mathrm{~kg})$ and a volume of liquid $V(L)$. The mass balance of such a system reads:

$m=V c+M X$

where $m$ is the mass of pesticide in the system $(\mathrm{mg})$. By combining with Eqn 1 , it can be derived that the percentage sorbed in the system $S$ is given by:

$$
S=100 \frac{R K}{1+R K}
$$

where $R=M / V$ (so $\mathrm{kg} / \mathrm{L}$ ). The value of $R$ in a stonewool system is typically $0.1 \mathrm{~kg} / \mathrm{L}$ (based on a volume fraction of water of 0.6 and a dry bulk density of $80 \mathrm{~g} / \mathrm{L}$; van der Maas et al., 2015; Matser and Leistra, 1997). This gives for pymetrozine a percentage sorbed of $2 \%$ and for dimethomorph a percentage sorbed of $9 \%$.

Table 5 Sorption coefficients measured for the two types of stonewool with the two methods. Numbers after ' \pm ' indicate sample standard deviations.

\begin{tabular}{|c|c|c|c|c|}
\hline & & \multicolumn{2}{|c|}{$\mathrm{K}(\mathrm{L} / \mathrm{kg})$} & \multirow[t]{2}{*}{ recovery (\%) } \\
\hline & & concentrations & extraction & \\
\hline pymetrozine & Cultilene & $0.6 \pm 0.4$ & $0.2 \pm 0.1$ & $98 \pm 2$ \\
\hline E-dimethomorph & Grotop & $0.4 \pm 0.2$ & $1.2 \pm 0.5$ & $104 \pm 3$ \\
\hline \multirow[t]{2}{*}{ Z-dimethomorph } & Grotop & $2.3 \pm 0.2$ & $1.5 \pm 0.4$ & $97 \pm 1$ \\
\hline & Cultilene & $1.6 \pm 0.4$ & $0.9 \pm 0.1$ & $97 \pm 2$ \\
\hline
\end{tabular}




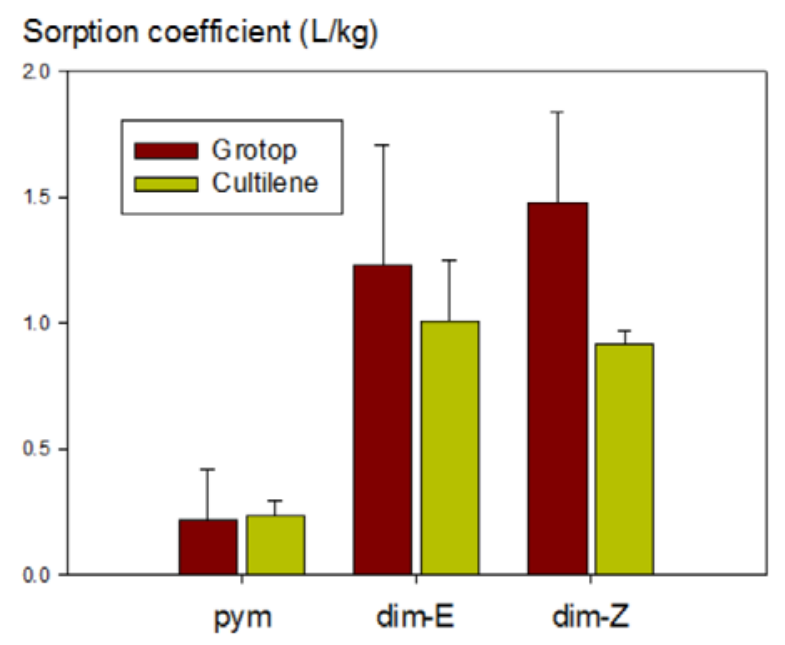

Figure 3 Sorption coefficients of pymetrozine, E-dimethomorph, and Z-dimethomorph as measured for Grotop and Cultilene stonewool in batch experiments using the methanol extraction procedure. The vertical line segments indicate standard deviations.

\subsubsection{Batch sorption studies with pipe materials and stonewool foil}

Table 6 and Table 7 show that all concentrations in the blank tubes were at the end of the experiment reasonably close to the concentrations added except one of the pymetrozine concentrations which was $109 \%$ of the added concentration. As described in Section 2.1.2, also for the pipe materials and the stonewool foil two methods were applied for the measurement of the sorption of the pesticides onto the clean stonewool: (1) based on the decrease in the concentration in the liquid phase before and after sorption equilibration, and (2) based on the mass of pesticide extracted from the solid phase with methanol at the end of the experiment.

Detailed results of all sorption measurements with pipe materials and stonewool foil are given in Annex 3. A summary of these results in Table 8 and Figure 4 shows that none of the measured sorption coefficients for pymetrozine differed significantly from zero, so it is concluded that this sorption was too low to be measured under these circumstances.

The measurement based on the methanol extraction is expected to generate more accurate results than that based on the concentration decrease unless the methanol extraction is incomplete for some reason: if this extraction is incomplete, the mass sorbed is underestimated because sorbed pesticide was not extracted. However, a recovery of less than $100 \%$ in Table 8 does not necessarily mean that the recovery was incomplete because there may have been some loss process other than sorption.

The summary of the results for dimethomorph in Table 8 and Figure 4 shows that the extraction for E-dimethomorph and the TP and DP materials was close to $100 \%$ and that the sorption coefficient based on the methanol extraction was much less variable than that based on the concentration decrease. So the best estimate for the sorption coefficient of E-dimethomorph is $0.07 \mathrm{~L} / \mathrm{kg}$ for the TP material and $0.14 \mathrm{~L} / \mathrm{kg}$ for the DP material. For the SF material the recovery of E-dimethomorph was only $86 \%$; it is quite likely that this recovery was incomplete because the SF material is a very thin foil that was cut into pieces which may have been partly sticked to each other during the extraction. So for this material, the sorption coefficient based on the concentration decrease $(1.5 \mathrm{~L} / \mathrm{kg})$ is considered more reliable than that based on the methanol extraction.

Following a similar reasoning, it is concluded for Z-dimethomorph that the sorption coefficients of TP and DP based on the methanol extraction $(0.12$ and $0.16 \mathrm{~L} / \mathrm{kg}$, respectively) are more reliable than those based on the concentration decrease and that for the SF material the coefficient based on the concentration decrease $(1.2 \mathrm{~L} / \mathrm{kg})$ is more reliable than that based on the methanol extraction. 
Using the mass-volume ratios from Table 2, the percentage sorbed to the pipe materials and the foil can be estimated with Eqn 3 assuming sorption equilibrium and perfect mixing of water in the pipes and in the mats. However, it should be realised that only the inner parts of the pipes and the foil is in contact with the pesticides in the actual system whereas also the outer parts of the pipes and the foil were included in the batch sorption studies. Let us assume that the sorption to outer and inner parts was equal. Then we have to take $50 \%$ of the measured sorption coefficients. This gave the following percentages sorbed for the isomers of dimethomorph: for TP 1-2\% (using $K$ range of 0.035-0.06 $\mathrm{L} / \mathrm{kg}$ ), for DP 8-9\% (using $K$ range of $0.07-0.08 \mathrm{~L} / \mathrm{kg}$ ) and for SF 2\% (using $K$ range of 0.6-0.75 L/kg). These are comparatively low percentages.

Table 6 Pesticide concentrations in the solution added to tubes without solid materials and pesticide concentrations in these tubes at the end of experiment with the TP and DP materials. All concentrations are expressed as percentages of the average initial concentrations (i.e. $102 \mu \mathrm{g} / \mathrm{L}$ pymetrozine, $35 \mu \mathrm{g} / \mathrm{L}$ E-dimethomorph, $54 \mu \mathrm{g} / \mathrm{L} \mathrm{Z}$-dimethomorph, $89 \mu \mathrm{g} / \mathrm{L}$ for the sum of the isomers).

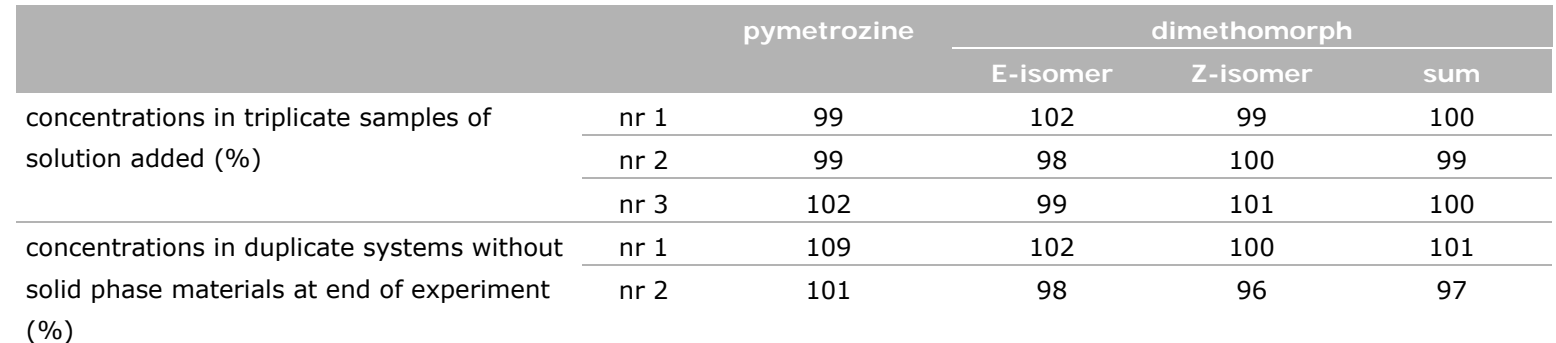

Table 7 Pesticide concentrations in the solution added to tubes without solid materials and pesticide concentrations in these tubes at the end of experiment with the SF material. All concentrations are expressed as percentages of the average initial concentrations (i.e. $104 \mu \mathrm{g} / \mathrm{L}$ pymetrozine, $39 \mu \mathrm{g} / \mathrm{L}$ E-dimethomorph, $53 \mu \mathrm{g} / \mathrm{L} \mathrm{Z}$-dimethomorph, $92 \mu \mathrm{g} / \mathrm{L}$ for the sum of the isomers).

\begin{tabular}{|c|c|c|c|c|c|}
\hline & & \multirow[t]{2}{*}{ pymetrozine } & \multicolumn{3}{|c|}{ dimethomorph } \\
\hline & & & E-isomer & Z-isomer & sum \\
\hline $\begin{array}{l}\text { concentrations in duplicate samples of } \\
\text { solution added }(\%)\end{array}$ & $\mathrm{nr} 1$ & 104 & 101 & 99 & 99 \\
\hline \multirow{2}{*}{$\begin{array}{l}\text { concentrations in duplicate systems without } \\
\text { solid phase materials at end of experiment } \\
(\%)\end{array}$} & $\mathrm{nr} 1$ & 102 & 94 & 100 & 97 \\
\hline & $\mathrm{nr} 2$ & 105 & 98 & 105 & 102 \\
\hline
\end{tabular}

Table 8 Overview of sorption coefficients measured for the TP, DP and SF materials with the two methods. Numbers after ' \pm ' indicate sample standard deviations.

\begin{tabular}{|c|c|c|c|c|}
\hline & & \multicolumn{2}{|c|}{$\mathrm{K}(\mathrm{L} / \mathrm{kg})$} & \multirow[t]{3}{*}{ recovery (\%) } \\
\hline & & & & \\
\hline & & concentrations & extraction & \\
\hline \multirow{2}{*}{ pymetrozine } & DP & $-0.05 \pm 0.03$ & $0.02 \pm 0.02$ & $103 \pm 2$ \\
\hline & SF & $-0.16 \pm 0.22$ & $-0.09 \pm 0.12$ & $101 \pm 4$ \\
\hline \multirow{2}{*}{ E-dimethomorph } & DP & $0.26 \pm 0.07$ & $0.14 \pm 0.02$ & $96 \pm 3$ \\
\hline & SF & $1.49 \pm 0.17$ & $0.16 \pm 0.05$ & $86 \pm 2$ \\
\hline \multirow[t]{2}{*}{ Z-dimethomorph } & TP & $0.26 \pm 0.07$ & $0.12 \pm 0.02$ & $94 \pm 2$ \\
\hline & DP & $0.37 \pm 0.07$ & $0.16 \pm 0.03$ & $93 \pm 3$ \\
\hline
\end{tabular}



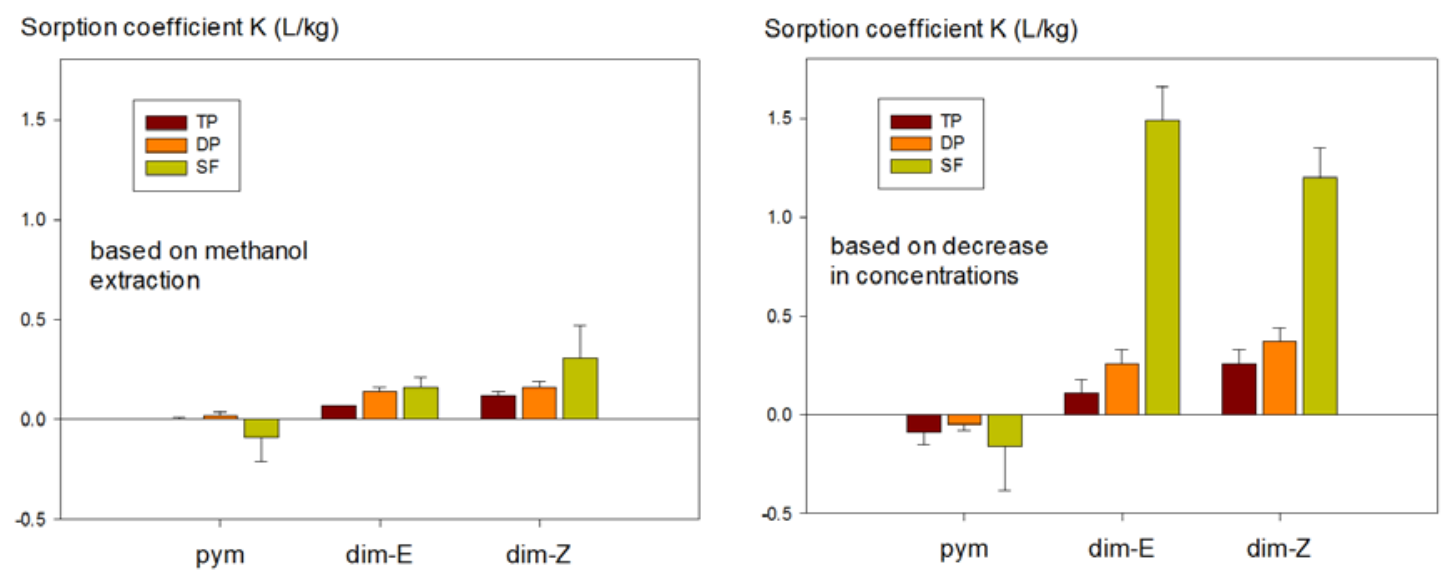

Figure 4 Sorption coefficients of pymetrozine, E-dimethomorph, and Z-dimethomorph as measured for transport pipes (TP), drip pipes (DP) and stonewool foil (SF) in batch experiments. The vertical line segments indicate standard deviations. 


\section{Circulation studies with stonewool mats}

\subsection{Materials and methods}

\subsubsection{Introduction}

The purpose of the laboratory experiments was to test whether the sorption to an 'intact' stonewool system is higher than to the clean stonewool as reported in Chapter 2. An intact stonewool system contains also plant roots which may lead to some additional sorption. Furthermore during the cropping period some organic matter may be formed in the system that may also lead to additional sorption. Thus the experiments were done for a sweet-pepper system at the end of its growing cycle.

The principle of the experiments was to circulate a solution containing the pesticides through the system for approximately $6 \mathrm{~h}$ and to measure the course of time of the pesticide concentrations. If no sorption occurs (and no other loss processes), the concentration of each pesticide is expected to become equal after some time to the average initial concentration in the water in the system. If sorption occurs, the concentration is expected to decrease below this level.

\subsubsection{Sampling of the plant systems}

On 7 November 2016 mats of stonewool (Cultilene) were collected from a WUR greenhouse in Bleiswijk (the Netherlands). In this greenhouse sweet pepper was grown which was almost at the end of its growing cycle. Plants were 3-4 m high and the sweet peppers were located mostly in the upper metre of the plants (Figure 5).

Three pieces of mats were sampled with a length of about $30 \mathrm{~cm}$ in such a way that a plant was located in the centre of each mat. The plants were cut at a height of about $40 \mathrm{~cm}$ to enable transport and handling. Each mat was put into a plastic bucket $(30 \times 20 \times 20 \mathrm{~cm}$; Figure 5). The Cutilene stonewool mats were $10 \mathrm{~cm}$ wide and $7.5 \mathrm{~cm}$ deep. The mats were transferred to the laboratory and experiments with these mats were conducted on 8 and 10 November.

The greenhouse was treated with pymetrozine on 15 July, 5 October and 14 October to control aphids. No dimethomorph was applied.
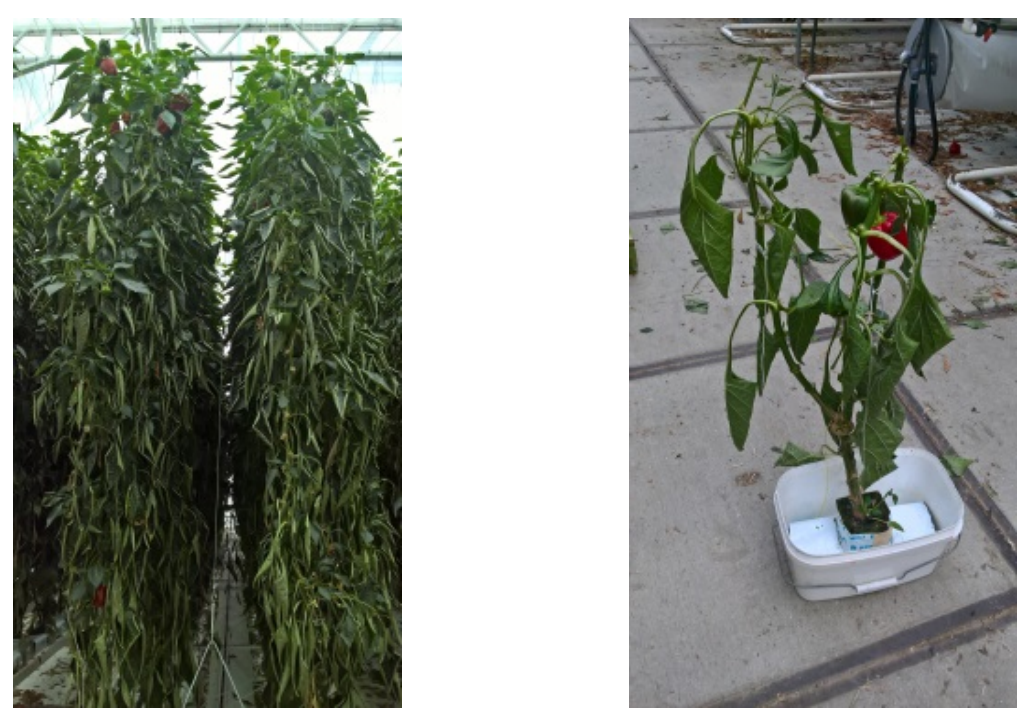

Figure 5 Photographs of the sweet pepper greenhouse and of one of the sampled plant systems. 


\subsubsection{Procedures of the laboratory experiments}

The system consisted of a stonewool mat in a sampling bucket through which $\mathrm{Ca}\left(\mathrm{NO}_{3}\right)_{2}$ solution containing the pesticides was circulated with help of a tube pump and Versilic tubes (silicon). Starting from the pump and going in the direction of water flow, the system consisted of (1) $2.5 \mathrm{~m}$ Versilic tube with inner- and outer diameters of 5 and $8 \mathrm{~mm}$, (2) a valve to sample the inflow, (3) $0.9 \mathrm{~m}$ Versilic tube with inner- and outer diameters of 4 and $6 \mathrm{~mm}$, (4) $0.3 \mathrm{~m}$ blue tube connected to syringes pierced into the mat (Figure 6), (5) the mat in the bucket, (6) 0.4-0.5 m Versilic tube with inner- and outer diameters of 4 and $6 \mathrm{~mm},(7)$ a valve to sample the outflow, (8) $1.2 \mathrm{~m}$ Versilic tube with inner- and outer diameters of 4 and $6 \mathrm{~mm},(9)$ a glass flask, (10) $1 \mathrm{~m}$ Versilic tube with innerand outer diameters of 4 and $6 \mathrm{~mm}$ (see Annex 4 for a schematic representation of this system).

This solution was dripped on the mats from some ten needles pierced into the mats to promote an even distribution of the water flow through the mats (Figure 6). The solution was circulated at a speed of $86 \mathrm{~mL} / \mathrm{min}$ (so about $5 \mathrm{~L} / \mathrm{h}$ ).

Experiments as described above were conducted with the three sampled plant systems. Furthermore one experiment was conducted with a system without stonewool (so with an empty bucket) and another experiment with a system with a 'clean' stonewool mat, i.e. as delivered from the factory. So there were five systems which will be further called 'empty bucket', 'clean stonewool', 'plant $A^{\prime}$, 'plant $B$ ' and 'plant $C$ '. The experiments with plants $A$ and $B$ were conducted on 8 November and that with plant $\mathrm{C}$ was conducted on 10 November.

For each experiment $3.000 \mathrm{~L}$ of a solution was prepared using distilled water containing $0.02 \mathrm{~mol} / \mathrm{L}$ $\mathrm{Ca}\left(\mathrm{NO}_{3}\right)_{2}$ and $5.0-6.0 \mathrm{mg} / \mathrm{L}$ pymetrozine $(1.2 \mathrm{mg} / \mathrm{L}$ for the empty-bucket system) and $1.3-1.6 \mathrm{mg} / \mathrm{L}$ dimethomorph. The concentration of the $Z$-isomer of dimethomorph in the solution was about 1.7 times that of the E-isomer. For pymetrozine, a higher concentration was used for the experiments with the plant systems because pymetrozine had been applied to the sweet pepper so some background concentration of pymetrozine could be expected.

In the empty-bucket and the clean-stonewool systems, the water in the system was limited to the 3-L solution that was prepared. The plant systems contained of course some water at the start. Furthermore at the start of each plant experiment, a volume of $2.3 \mathrm{~L}$ of clean $\mathrm{Ca}\left(\mathrm{NO}_{3}\right)_{2}$ solution was circulated for 1-2 $\mathrm{h}$ through the systems to be able to detect a possible background level of the pesticides. After addition of the solution containing the pesticides, the solution in the systems was circulated for about $6 \mathrm{~h}$ and samples of inflow and outflow were taken at regular intervals. The concentrations of pymetrozine and dimethomorph was measured as described in Section 2.1.3. 

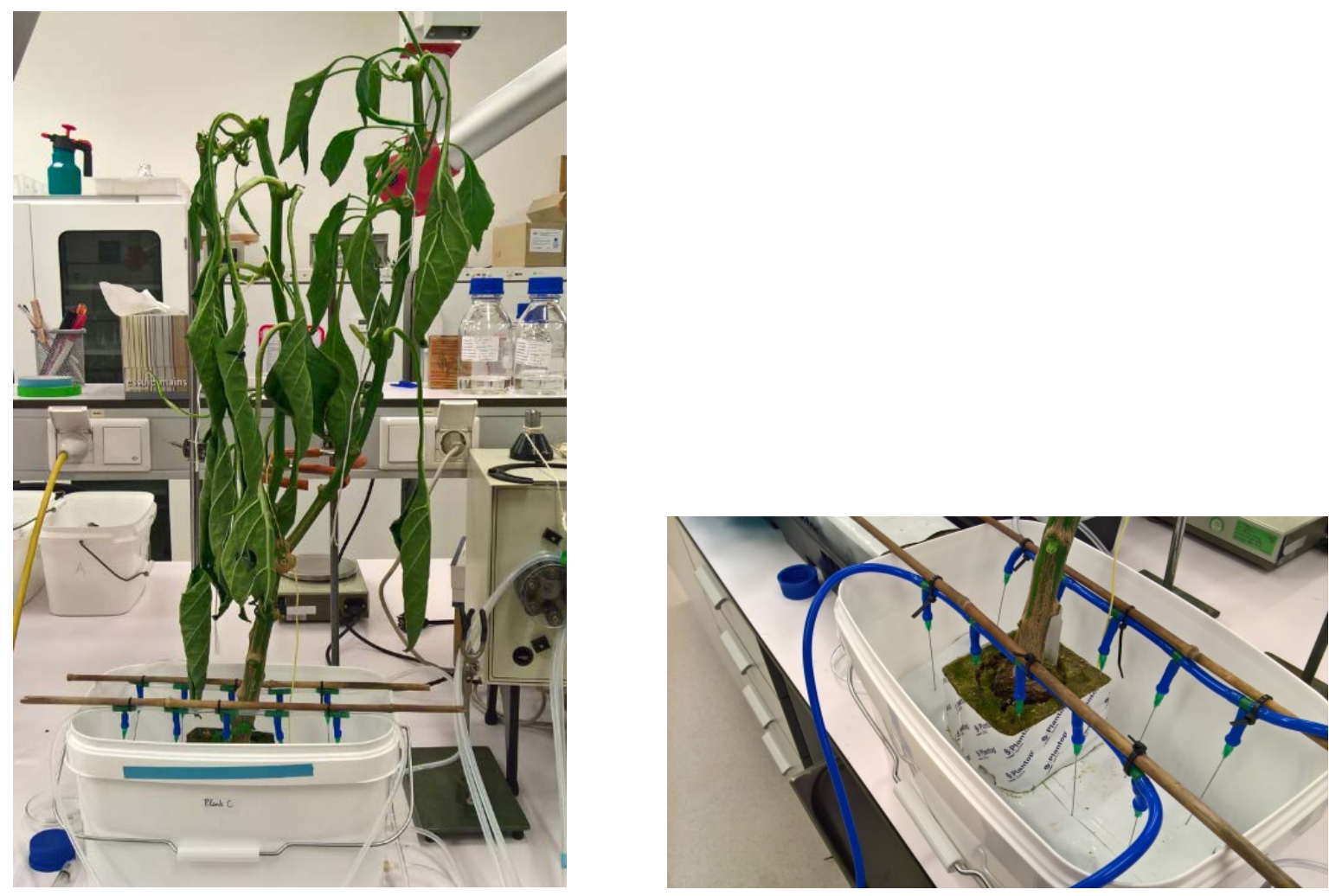

Figure 6 Photographs of a plant system in a bucket in the laboratory (left) and of the ten needles pierced into the mat used to distribute the solution on top of the system (right). Note the block with the plant on top of the mat (right). Four needles are placed in the block and six in the mat below.

In the experiment with the empty-bucket system, the top of the bucket was covered with aluminium foil but with an opening of $10 \times 10 \mathrm{~cm}$ to mimick the $10 \times 10 \mathrm{~cm}$ surface area of the pots in the plant systems from which also water could evaporate (see Figure 6 ). The plant systems were loosely wrapped in aluminium foil during the pumping period.

At the end of the plant experiment, the above-ground parts of the plants were cut off and the masses of water and dry material in each mat was measured by drying during one week at $80^{\circ} \mathrm{C}$.

The organic matter contents of the mats of the plant systems were measured using the dried mats by first removing all plant roots present at the bottom of the mat, and then taking three subsamples of the mat (one in the middle and two at the ends). The mass of organic matter was measured by loss on ignition (overnight at $550^{\circ} \mathrm{C}$ ) both for the three subsamples and all plant-root material from each mat. As stonewool consist partly of $\mathrm{CaCO}_{3}$, the ignition will also release some $\mathrm{CO}_{2}$ from the stonewool. Therefore the loss on ignition of clean stonewool was measured as well in four subsamples. The mass lost divided by the remaining mass after ignition was found to be on average 0.069 with a standard deviation of 0.005 . So the mass losses were lowered by $6.9 \%$ to derive the organic matter contents.

As will be described below, the empty-bucket experiment showed a significant decrease in the dimethomorph concentration. Extraction of a few pieces of the plastic tubes at the end of the experiment indicated that this was caused by sorption to these tubes. To be able to quantify the mass sorbed to the tubes, at the end of the other four experiments, the tubes were flushed with acetone or methanol (for 45 min with acetone for plants $A$ and $B$ and for $2 \mathrm{~h}$ with methanol for plant $\mathrm{C}$ and clean stonewool; see Table 9 for amounts of solvents). The problem with the acetone was that the tubes started to crack after some 45 min causing considerable leakage of acetone, so therefore methanol was used for the plant- $\mathrm{C}$ and clean-stonewool systems. The concentrations in the solvents and their volumes were measured and the masses extracted by the flushing were calculated based on the added masses of solvent. 
Table 9 Amounts of organic solvent used and recovered for the flushing of the tube systems at the end of the experiments.

\begin{tabular}{ccccc} 
system & type of solvent & \multicolumn{2}{c}{$\begin{array}{c}\text { mass of solvent (g) } \\
\text { added }\end{array}$} & $\begin{array}{c}\text { recovercentage solvent } \\
\text { recovered }\end{array}$ \\
plant A & acetone & 437 & 234 & 54 \\
\hline plant B & acetone & 438 & 317 & 72 \\
\hline plant C & methanol & 642 & 593 & 92 \\
\hline clean stonewool & methanol & 730 & 694 & 95 \\
\hline
\end{tabular}

\section{Processing of the results}

The aim of the study was to quantify the possible decrease in concentration of the pesticides resulting from sorption to materials in the mats. Therefore all concentrations will be presented as percentages of the so-called 'perfectly-mixed concentration' (acronym PMC). This concentration is defined as the concentration in the liquid phase of the systems assuming perfect mixing in the systems and assuming no sorption to the materials in the mats. However, the PMC does not include the mass recovered by flushing with organic solvent at the end of the study because this mass is of no interest for the processes in the mats.

This PMC was calculated for each pesticide (with separate calculations for the E- and Z-isomers of dimethomorph) as follows:

\# the total mass of water in the system was assumed to be equal to the total mass in the mats at the start plus the mass retained by the mats due to the circulation of the pesticide-free solution plus the total mass of the pesticide solution added to each system;

\# the total mass of each pesticide in the system was assumed to be equal to the mass of this pesticide in the pesticide solution that was added to each system minus the mass of this pesticide that was recovered by the flushing with organic solvent at the end of the study.

The calculation of the PMC as described above was impossible for the empty-bucket system because no flushing of tubes with solvent was performed. Therefore the concentrations for this system are given as percentage of initial concentrations.

\subsection{Results}

During the initial circulation of the pesticide-free solution, concentrations of pymetrozine up to 0.06 , 0.01 and $0.03 \mathrm{mg} / \mathrm{L}$ were detected in the plant-A, plant-B and plant-C systems, respectively (resulting from the pymetrozine applications in the greenhouse described before). These were ignored in all calculations because they were no more than $1 \%$ of the concentration of pymetrozine in the added pesticide solution.

The overview of the elements of the water balance in the experiments (Table 10) shows that the masses of the dry mats in the plant systems ranged between about 200 and $260 \mathrm{~g}$. The ratio of the mass of water divided by the mass of dry mat at the end of the experiment ranged between 9 and 11 for the plant systems and was only 7 for the clean-stonewool system. Obviously the presence of roots and some accumulation of organic matter led to an increased water retention. The loss of water from the systems ranged between 2 and 4\% except for plant B which showed a much greater loss. This loss from plant $B$ was caused by a leakage of the tubing system which led to loss of a considerable amount of water. The loss from the plant-A and plant-C systems was 100-130 g higher than the loss from the clean-stonewool system. This may have been the result of transpiration from the plant systems. 


\begin{tabular}{|c|c|c|c|c|c|}
\hline & \multicolumn{5}{|c|}{ system } \\
\hline & $\begin{array}{l}\text { empty } \\
\text { bucket }\end{array}$ & $\begin{array}{l}\text { clean } \\
\text { stonewool }\end{array}$ & plant A & plant B & plant C \\
\hline mass ( $\mathrm{g}$ ) of dry mat without above ground parts & & 131 & 199 & 235 & 261 \\
\hline mass $(g)$ of water in mat at start & & & 1782 & 2060 & 1490 \\
\hline $\begin{array}{l}\text { mass }(\mathrm{g}) \text { of water retained in mat after circulation of } \\
\text { pesticide-free solution }\end{array}$ & & & 475 & 556 & 926 \\
\hline $\begin{array}{l}\text { mass }(\mathrm{g}) \text { of water in circulation system at start of } \\
\text { circulation of pesticide solution }\end{array}$ & 3000 & 3000 & 5257 & 5616 & 5417 \\
\hline $\begin{array}{l}\text { mass of water in mat divided by mass of dry mat } \\
\text { after circulation of pesticide-free solution }\end{array}$ & & & 11.3 & 11.1 & 9.3 \\
\hline mass $(\mathrm{g})$ of water in mat at end & & 907 & 2068 & 2643 & 2404 \\
\hline $\begin{array}{l}\text { mass of water in mat divided by mass of dry mat at } \\
\text { end }\end{array}$ & & 6.9 & 10.4 & 11.2 & 9.2 \\
\hline mass $(\mathrm{g})$ of water lost from system & 49 & 76 & 176 & 928 & 205 \\
\hline $\begin{array}{l}\text { percentage of water lost from system based on total } \\
\text { mass of water in system just after adding pesticide } \\
\text { solution }\end{array}$ & 2 & 3 & 3 & 17 & 4 \\
\hline
\end{tabular}

Figure 7 shows that flushing with solvents released only $0.2-0.3 \%$ of the dosed mass of pymetrozine. However, it released $7-8 \%$ of the E- and Z-isomers of dimethomorph in the plant systems and $12 \%$ in the clean-stonewool system. The difference between the plant systems and the clean-stonewool system can be explained from the difference in the water volumes in these systems (on average $5.4 \mathrm{~L}$ for the plant systems based on Table 10 and $3 \mathrm{~L}$ for the clean-stonewool system). Assuming a linear sorption coefficient for the sorption to the plastic tubes and $8 \%$ of total mass sorbed to the plastic tubes for a volume of $5.4 \mathrm{~L}$ (using Eqns 1, 2 and 3), generated a predicted percentage of total mass sorbed to the plastic tubes of $13.5 \%$ for a volume of $3.0 \mathrm{~L}$ which is close to the observed $12 \%$ for the clean-stonewool system. The consistency in the results for dimethomorph for the different solvent systems and the different water volumes in Figure 7 suggest that the recovery of the dimethomorph from the plastic tubes was close to complete.

As described before, the calculation of the PMC was based on the masses of water added to the system. In view of the low loss percentages for all systems except plant B this seems justifiable. For the plant-B system this seems justifiable as well because the leakage occurred a few hours after the start of the experiment (so the water that leaked did sufficiently participate in the equilibration process). Table 11 gives the PMC values for all substance-system combinations.

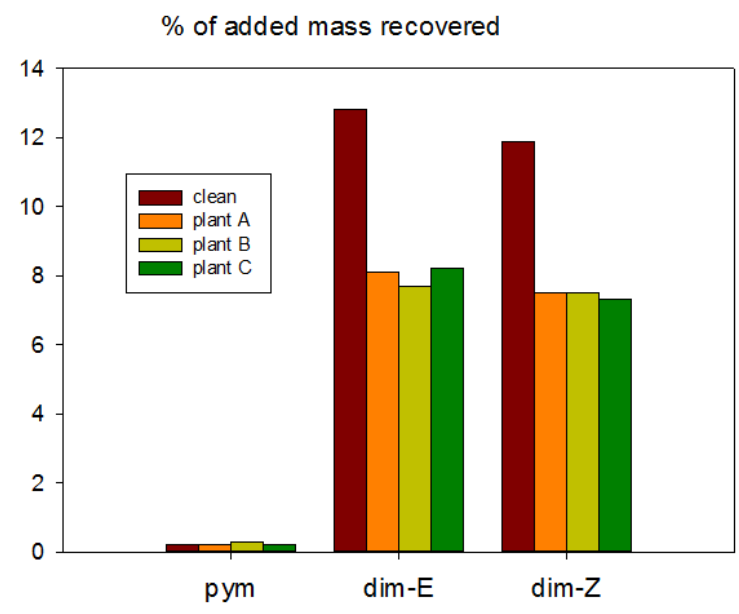

Figure 7 Percentage of total added mass of pesticide (pymetrozine, E-dimethomorph, and $Z$-dimethomorph) hat was recovered by flushing the tube systems with acetone (plants $A$ and $B$ ) and methanol (plant $C$ and clean stonewool) at the end of the experiments. 
Table 11 The 'perfectly-mixed concentration' (PMC) in $\mathrm{mg} / \mathrm{L}$ of all substances for the plant and clean-stonewool systems and the initial concentration $(\mathrm{mg} / \mathrm{L})$ of all substances for the empty-bucket system.

\begin{tabular}{|c|c|c|c|c|c|}
\hline & \multicolumn{5}{|c|}{ system } \\
\hline E-dimethomorph & 0.51 & 0.44 & 0.26 & 0.29 & 0.29 \\
\hline Z-dimethomorph & 0.82 & 0.77 & 0.46 & 0.50 & 0.50 \\
\hline
\end{tabular}

As shown in Figure 8, the concentration of pymetrozine in the empty-bucket system remained always close to the initial concentration. Obviously no measurable sorption of pymetrozine to the plastic tubes occurred (consistent with Figure 7). However, even the first inflow concentrations of E- and Z-dimethomorph were significantly below the initial concentration, indicating rapid sorption to the plastic tubes. The dimethomorph concentrations decreased gradually to about $75 \%$ of initial. From the water solubilities and the saturated vapour pressures in Table 1, an air-water partitioning coefficient (Henry coefficient) of about $10^{-9}$ can be calculated for pymetrozine and of about $10^{-8}$ for the isomers of dimethomorph, so volatilisation of these substances can be excluded as a loss process. Both pymetrozine and dimethomorph are hydrolytically stable according to the PPDB database so hydrolysis can also be excluded as a significant loss process. As described before, the plastic tubes were not flushed with solvent at the end of the experiment with the empty bucket so it is unknown how much was sorbed to these tubes. However, one would expect for this empty-bucket system about the same percentage sorbed to the tubes as in the clean-stonewool system which had $12 \%$ sorbed to the tubes (Figure 7).

In the clean-stonewool system, the concentration of pymetrozine remained mostly close to $100 \%$ of the PMC (Figure 8). The concentrations were usually slightly higher than $100 \%$ which may be the result of the $3 \%$ evaporation of water (Table 10). The concentration of the isomers of dimethomorph decreased after a few hours to about $90 \%$ of the PMC. However there was a clear outlier in an outflow sample (both the $E$ and the $Z$ isomer) around $13 \mathrm{~h}$; probably something went wrong with this sample. This $90 \%$ of the PMC for the isomers of dimethomorph can be compared with a prediction from the batch experiments with stonewool. As described in Section 2.2.1, the sorption coefficient was estimated to be $1 \mathrm{~L} / \mathrm{kg}$. This system consisted of $131 \mathrm{~g}$ of stonewool (Table 10) and $3 \mathrm{~L}$ of water. 

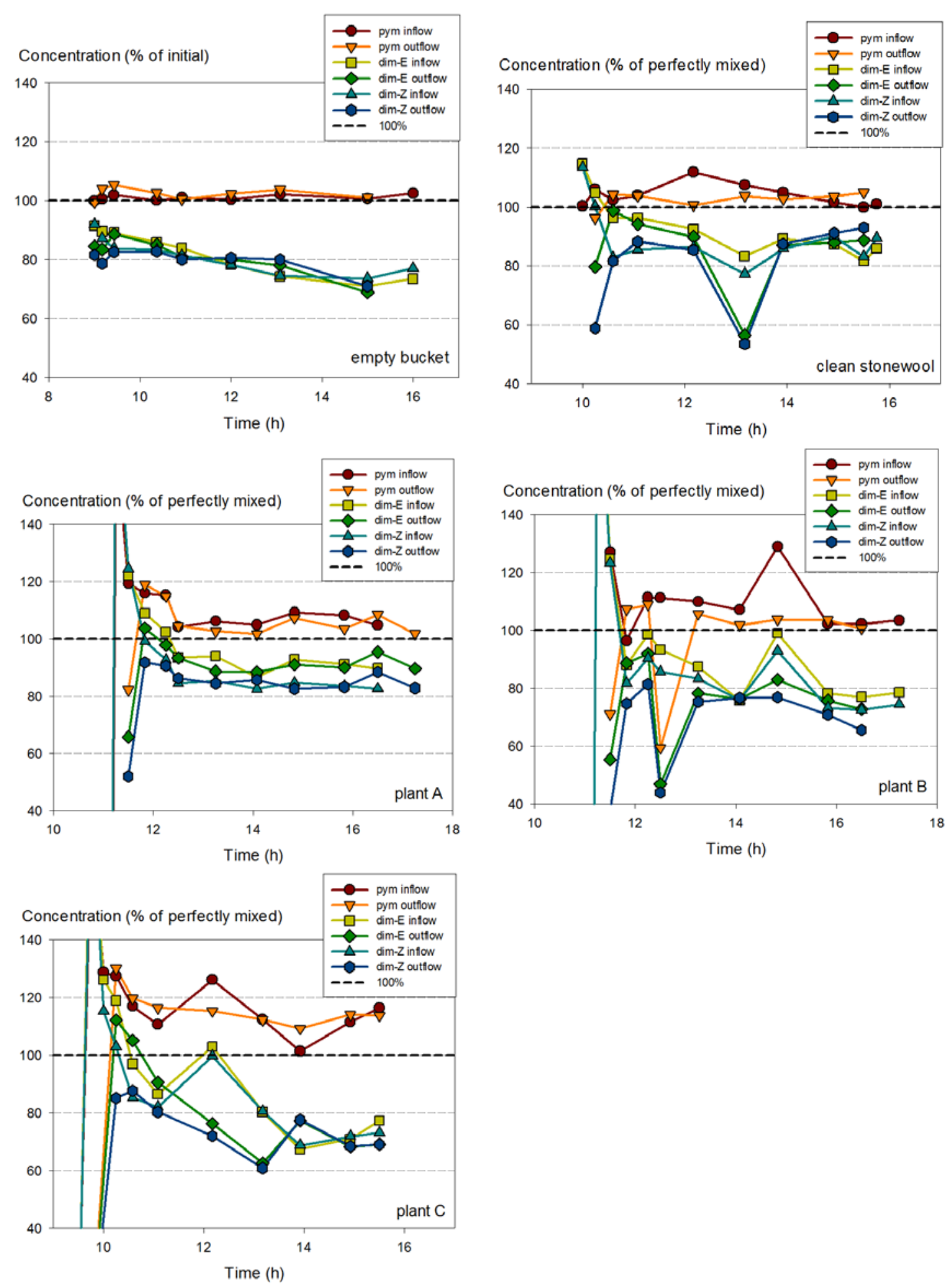

Figure 8 Pesticide concentrations in the inflowing and outflowing water flows in the experiments with the empty-bucket, clean-stonewool, plant- $A$, plant- $B$ and plant- $C$ systems as a function of daytime. The concentrations of the empty-bucket system are in \% of initial and those of the other systems in \% of the PMC of each pesticide-system combination; pym= pymetrozine, dim- $E=E$-isomer of dimethomorph, dim-Z = Z-isomer of dimethomorph. Note that the vertical axis starts at $40 \%$. 
Using Eqn 3, it then follows that the percentage sorbed is 4\%. Considering the 3\% evaporation of water, one would thus expect $99 \%$ of the PMC instead of the observed $90 \%$. It is thus likely that there was a loss process of about $10 \%$ that was unaccounted for (possibly sorption of dimethomorph molecules to the plastic tubes that were not released by the flushing with organic solvent).

This conclusion for the clean-stonewool system is consistent with the result for the empty-bucket system: the loss from the clean-stonewool system was $12 \%$ as extracted with organic solvent (Figure 8 ) plus about $10 \%$ unaccounted loss, so in total $22 \%$ which is consistent with the dimethomorph concentrations decreasing to about $75 \%$ of initial in the empty-bucket system. So for the plant systems it has to be kept in mind that about $10 \%$ lowering of the PMC for the isomers of dimethomorph may be the result of an experimental artifact.

The concentrations of pymetrozine for the three plant systems in Figure 8 are mostly between 100 and $110 \%$. Concentrations up to $103-104 \%$ could be expected because of the evaporation loss of the water (Table 10) if no pymetrozine would have been taken up by the plant. A possible explanation of the values of around $110 \%$ is that the mixing of the water in these mats was not perfect (especially for plant C; as described before, there was about 2-3 $L$ of water in the mats at the start of the circulation experiments with the plant systems to which $3 \mathrm{~L}$ of solution containing the pesticides was added).

The concentrations of the isomers of dimethomorph in the plant- $\mathrm{A}$, plant-B and plant- $\mathrm{C}$ systems at the end of the experiment were about 90,75 , and $70 \%$ for the E-isomer and about 85,70 and $70 \%$ for the Z-isomer (Figure 8), so on average about $80 \%$, i.e. $10 \%$ lower than expected on the basis of the experiments with the empty-bucket and the clean-stonewool system. This $10 \%$ may seem a low number. However, it should be realised that the percentage sorbed in this circulation system differs from the percentage sorbed in the real system in the greenhouse. Background is that in the circulation system the ratio of mass of solid phase to volume of liquid is about $0.2 / 5.4=0.04 \mathrm{~kg} / \mathrm{L}$ whereas this ratio is about $0.1 \mathrm{~kg} / \mathrm{L}$ in the real system. This is illustrated with Figure 9: some $10 \%$ sorbed at a ratio of $0.04 \mathrm{~kg} / \mathrm{L}$ corresponds with a $K$ of about $3 \mathrm{~L} / \mathrm{kg}$ which gives about $20 \%$ sorbed for a ration of $0.1 \mathrm{~kg} / \mathrm{L}$. Based on Figure 9 this $10 \%$ can also be interpreted as an 'effective' sorption coefficient of about $3 \mathrm{~L} / \mathrm{kg}$ for dimethomorph at the end of the sweet-pepper growing cycle, so three times the value measured in the batch experiments with clean stonewool.

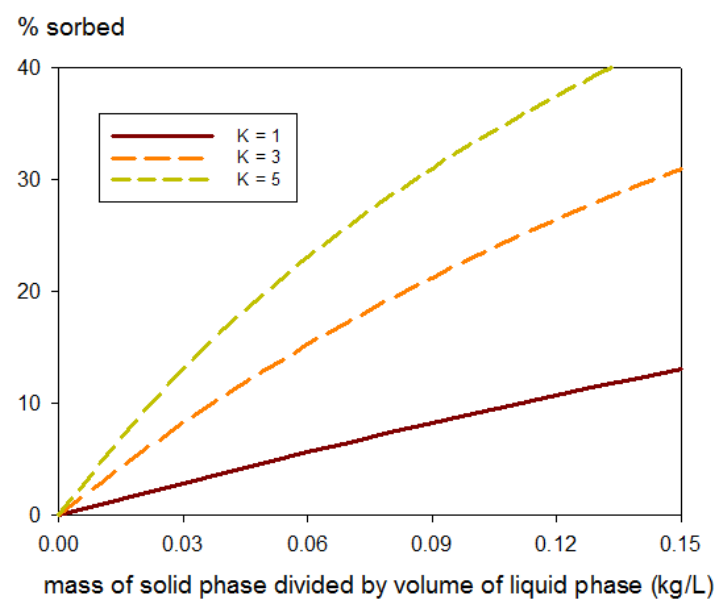

Figure 9 Percentage sorbed in a solid-liquid system as a function of the solid-liquid ratio as calculated with Eqn 3 for three values of the sorption coefficient $K$ as indicated in $\mathrm{L} / \mathrm{kg}$. 
The organic matter percentages of the mats varied strongly (Table 12). For each mat the highest percentage was found in the sample from the middle. This is understandable because the stem of the plant is located in the middle. Averages of each mat (based on the three subsamples) ranged between 13 and $22 \%$. Table 12 shows also that the organic matter from the roots that were collected separately from the bottom of each mat (Section 3.1.3) corresponded only to an additional $2-3 \%$ of organic matter.

Table 12 Measured mass fractions of organic matter (\%) in the stonewool mats. This mass fraction is defined as $100 \times$ the mass lost on ignition divided by the remaining mass after ignition. Mass fractions measured from stonewool samples were lowered by $6.9 \%$ to correct for the loss on ignition from clean stonewool.

\begin{tabular}{lcccc} 
& \multicolumn{3}{c}{ plant system } \\
\cline { 2 - 4 } sample from start of mat & A & B & C \\
\hline sample from middle of mat & 13 & 19 & 7 \\
\hline sample from end of mat & 17 & 38 & 21 \\
\hline average from 3 samples & 13 & 22 & 12 \\
\hline additional from roots & 3 & 2 & 3 \\
\hline
\end{tabular}




\section{Discussion and conclusions}

\subsection{Batch sorption studies}

Measuring the content sorbed by extraction with organic solvent after removing as much supernatant as possible has been considered a more accurate measurement method than the alternative procedure where the content sorbed is derived from the decrease in the concentration in the liquid phase (see Section 2.1.1 and Boesten, 1990). The batch adsorption studies with the stonewool foil and the isomers of dimethomorph showed that this is only true if the recovery of the extraction procedure is complete enough. So in any sorption study it seems advisable to check the plausibility of the recovery percentage.

In Section 2.2.1 we concluded to a sorption coefficient of 0.2 for pymetrozine and of $1.0 \mathrm{~L} / \mathrm{kg}$ for the isomers of dimethomorph. Crum et al. (1985) and Matser \& Leistra (1997) also measured sorption of pesticides to stonewool in batch experiments. Crum et al. used initial concentration levels of 2-17 $\mathrm{mg} / \mathrm{L}$, an equilibration time of $24 \mathrm{~h}$ and a solid-liquid ratio of $0.04 \mathrm{~kg} / \mathrm{L}$. They found a sorption coefficient of $1.8 \mathrm{~L} / \mathrm{kg}$ for etridiazole and of $2.0 \mathrm{~L} / \mathrm{kg}$ for tetrachlorvinphos; the sorption of ethoprophos was found to be too low to be measurable. The variation in the sorption coefficients between the replicates was considerable (CVs of 20-50\%). Matser \& Leistra measured sorption of oxamyl and metalaxyl at three concentration levels at equilibration times of 1 and $24 \mathrm{~h}$ using a solid-liquid ratio of $0.04 \mathrm{~kg} / \mathrm{L}$. For metalaxyl, they found a systematic difference between the concentration levels: the equilibrium concentration was on average $79 \%, 98 \%$ and $102 \%$ of the initial concentration for the three concentration levels $(0.1,1.1$ and $9.23 \mathrm{mg} / \mathrm{L})$. Matser \& Leistra wrote 'possibly, only a limited number of interaction sites was available in the rockwool'. Based on the $79 \%$ we calculated a sorption coefficient of $8 \mathrm{~L} / \mathrm{kg}$ which is very high given the log $K_{\text {ow }}$ of 1.75 of metalaxyl as will be shown below. So we consider these measurements for metalaxyl not reliable. For oxamyl Matser \& Leistra found rapid degradation during the batch equilibration $(80 \%, 100 \%$ and $65 \%$ decline at the three concentration levels after $24 \mathrm{~h}$ ). They showed that this was the result of transformation into the metabolite oxamyl-oxime so no sorption coefficient could be measured for oxamyl.

So the sorption coefficients of etridiazole and tetrachlorvinphos can be compared to our results. It can be expected that hydrophobic pesticides sorb stronger than lipophylic pesticides, so a positive correlation with the octanol-water partition coefficient can be expected. Figure 10 shows indeed a consistent relationship.

The $K_{\text {ow }}$ of ethoprophos is about 1000 , so based on Figure 10 a sorption coefficient above $1 \mathrm{~L} / \mathrm{kg}$ could be expected. Crum et al. did not provide an upper limit for the sorption coefficient of ethoprophos so this cannot be checked further. Figure 10 indicates that a sorption coefficient for metalaxyl of $8 \mathrm{~L} / \mathrm{kg}$ has to be considered very unlikely given the $K_{\text {ow }}$ of metalaxyl of about 60 (corresponding to log $K_{\text {ow }}$ of $1.75)$.

In Section 2.2.1 the concentration decrease in the stonewool system in the greenhouse was estimated at $9 \%$ for dimethomorph. In Section 2.2.2 the concentration decrease due to sorption to the drip irrigation pipes was estimated at $8-9 \%$ for dimethomorph. It is not clear whether these percentages sum up when estimating emission concentrations from greenhouses. Therefore, it is recommended to include sorption to stonewool and drip irrigation pipes in GEM to assess the combined effect of these processes on emission concentrations. 


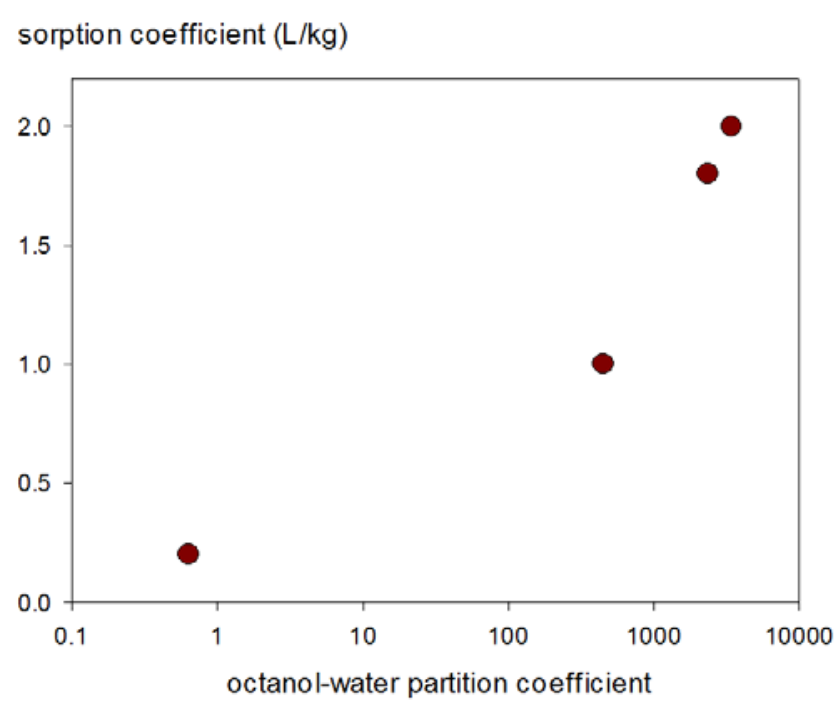

Figure 10 The sorption coefficient of four pesticides (pymetrozine, dimethomorph, etridiazole and tetrachlorvinphos) to stonewool as a function of their octanol-water partition coefficient.

\subsection{Circulation studies}

From the circulation studies we estimated that the concentration of the isomers of dimethomorph in the circulating solution was about $10 \%$ lower than expected from the experiments with the systems that did not contain roots. Roots are an important part of the organic matter in the stonewool mats. Briggs et al. (1982) established the following relationship between partitioning of pesticides into roots and the octanol-water partition coefficient:

$$
\log (R C F-0.82)=0.77 \log \left(K_{o w}\right)-1.52
$$

where RCF is the root concentration factor $(\mathrm{L} / \mathrm{kg})$ defined as the concentration in the roots divided by the concentration in the external solution (with concentration in roots defined as mass of pesticide in roots per mass of wet roots). It is worthwhile to test the hypothesis whether $10 \%$ lower concentration is consistent with the RCF predicted from Eqn 4. For dimethomorph ( $\log K_{\text {ow }}=2.6-2.7$ from Table 1) Eqn 4 gives a RCF of about $4 \mathrm{~L} / \mathrm{kg}$. The stonewool mats of the plant systems had about $200 \mathrm{~g}$ of dry mass (Table 10). Let us assume that $10 \%$ of these $200 \mathrm{~g}$ were dry roots (based on Table 12, considering only the samples at the start and the end of the mat because the samples from the middle of the mat may have contained a considerable fraction of woody root parts). So we have $20 \mathrm{~g}$ of dry roots. The ratio between fresh and dry root mass is assumed to be 10 , which gives $200 \mathrm{~g}$ wet root mass in each mat. Let us assume that the plant systems of the circulation studies consisted of $200 \mathrm{~g}$ of wet roots and $5.4 \mathrm{~L}$ of solution (this $5.4 \mathrm{~L}$ is the average water volume based on Table 10). The mass balance for such a system reads

$m=V c+M_{\text {roots }} R C F c$

where $M_{\text {roots }}$ is the mass of wet roots $(\mathrm{kg})$. Using Eqn 5, the percentage of total mass in the roots $W$ is given by

$W=100 \frac{M_{\text {roots }} R C F}{V+M_{\text {roots }} R C F}$

The parameters as described above give $W=13 \%$, so in line with the observed $10 \%$ lower concentration. In a greenhouse system, a mass of $200 \mathrm{~g}$ of dry mat corresponds with a $V$ of about $2 \mathrm{~L}$ (Table 10). For such a system $W$ is estimated to be $29 \%$ which indicates a significant decrease of the 
concentration due to partitioning into the roots. It is therefore concluded that partitioning into the roots should be included in the GEM model and that sensitivity of emission concentrations to this process should be assessed.

The log $K_{\text {ow }}$ of pymetrozine is -0.2 (Table 1 ). Eqn 4 gives then a $R C F$ of $0.84 \mathrm{~L} / \mathrm{kg}$ and Eqn 6 gives then $W=3 \%$. Such a low percentage could not be detected in the experiments with pymetrozine of Figure 8.

The $R C F$ relationship of Eqn 4 is based on studies in which substances are taken up by the roots and transported to the shoots. In the circulation studies the water uptake by the roots was very limited (as indicated by the 3-4\% loss of water in Table 10). It can be expected that contact between the solution and the roots is more intensive when water flows through the roots than when water passes the roots (i.e. the situation in the circulation experiments). So it is also possible that the additional $10 \%$ decrease in concentration is the result of sorption to organic matter formed during the course of the growing cycle. 


\section{References}

Boesten JJTI, 1990. Influence of solid/liquid ratio on the experimental error of sorption coefficients in pesticide/soil systems. Pesticide Science 30:31-41.

Briggs GG, Bromilow RH, Evans AA, 1982. Relationships between lipophilicity and root uptake and translocation of non-ionised chemicals by barley. Pestic. Sci. 13: 495-504.

Crum SJH, Runia WT, Leistra M, Smelt JH, 1985. Behaviour of some pesticides in a nutrient-film and in a rock-wool system. Scientia Horticulturae 25: 1-9.

EFSA, 2006. Conclusion regarding the peer review of the pesticide risk assessment of the active substance dimethomorph. EFSA Scientific Report 82, 1-69.

Matser AM, Leistra M, 1997. Pesticide behaviour in pumice and stonewool growth media. Adsorption and transformation of metalaxyl, oxamyl and carbendazim. Report 137.1, DLO Winand Staring Centre, $59 \mathrm{pp}$.

Van der Maas B, van der Staaij M, Eveleens B, Beerling E, van Os E, van Ruijven J, Wipfler L (2015). Toetsing emissiemodel substraatteelt. Experimenten op praktijkschaal en in laboratoriumopstelling. Rapport GTB-1340, Wageningen UR Glastuinbouw, 68 pp.

Van Ruiven J, van Os E, Blok C, Beerling E, 2016. Standaard water voor toetsing zuiveringstechnologie voor de glastuinbouw. Versie 2: geldend vanaf 1 januari 2016. WUR Glastuinbouw, Bleiswijk, January 2016, 3 pp. 


\section{Annex 1 Details of analytical procedures}

\section{Analytical system}

LC-MSMS

- Binary pump

- Column thermostat

- Degasser unit

- Autosampler

- Triple quad mass spectrometer

- ESI source

- software
Agilent 1200 (Agilent Technologies, Germany)

G1312A

G1316A

G1379B

G1329A

G6410A

G1948A

Agilent MassHunter

Separation

\begin{tabular}{lll}
\hline Injection volume: & $50 \mu$ or $100 \mu l$ \\
\hline mobile phase: & A: Milli Q water with $5 \mathrm{mM}$ ammoniumacetate $+0.1 \%$ formic acid \\
& B: Methanol with $5 \mathrm{mM}$ ammoniumacetate $+0.1 \%$ formic acid \\
\hline Gradient: & Time & Solvent Ratio B (\%) \\
& 0.0 & 10 \\
& 1.5 & 10 \\
& 4 & 60 \\
& 8 & 70 \\
& 11 & 100 \\
& 12 & 100 \\
& 12.01 & 10 \\
& 15 & 10 \\
\hline Flow: & 0.7 mL min ${ }^{-1}$ \\
\hline Column: & Agilent Analytical Zorbax XDB-C18, 150*4.6 mm column, 5 micron \\
\hline Column temperature: & $40{ }^{\circ} \mathrm{C}$ & \\
\hline Retention time: & Pymetrozine $\quad$ ca. 6.15 min \\
& E-Dimethomorph ca. 12.51 min \\
& Z-Dimethomorph ca. 12.86 min
\end{tabular}

\section{QQQ Detection}

Ionization mode

: ESI

Polarity

Capillary voltage

Dry temperature

Scan type
: positive

: 4000V

: $350{ }^{\circ} \mathrm{C}$

: MRM
Gas flow

Nebulizer pressure

Nebulizer gas

Collission gas
: $11 \mathrm{~L} / \mathrm{min}$

: 50 psi

: Nitrogen (98\% purity)

: Nitrogen (99.99\% purity) 


\begin{tabular}{llllll}
\hline Compound & Precursor ion & Product ion & Type & $\begin{array}{l}\text { Fragmentor } \\
\text { Voltage }\end{array}$ & Collision energy \\
\hline & $(\mathrm{m} / \mathrm{z})$ & $(\mathrm{m} / \mathrm{z})$ & & $(\mathrm{V})$ & $(\mathrm{V})$ \\
\hline Pymetrozine & 218.1 & 105 & quantifier & 145 & 17 \\
\cline { 3 - 4 } & & 78 & qualifier & & 49 \\
\hline Dimethomorph & 388.2 & 301.1 & quantifier & 85 & 10 \\
\hline
\end{tabular}

Injected samples were quantified by pymetrozine and E-dimethomorph and Z-dimethomorph peak area using the calibration curve constructed from calibration standards The concentrations of the samples never exceeded the highest standard of the calibration curve. The curve fit was quadratic and forced through origin ( $x$-axis zero; $y$-axis zero).

\section{Chromatograms and calibration curves of pymetrozine and dimethomorph}

\section{Standard Pymetrozine 264 ppb}

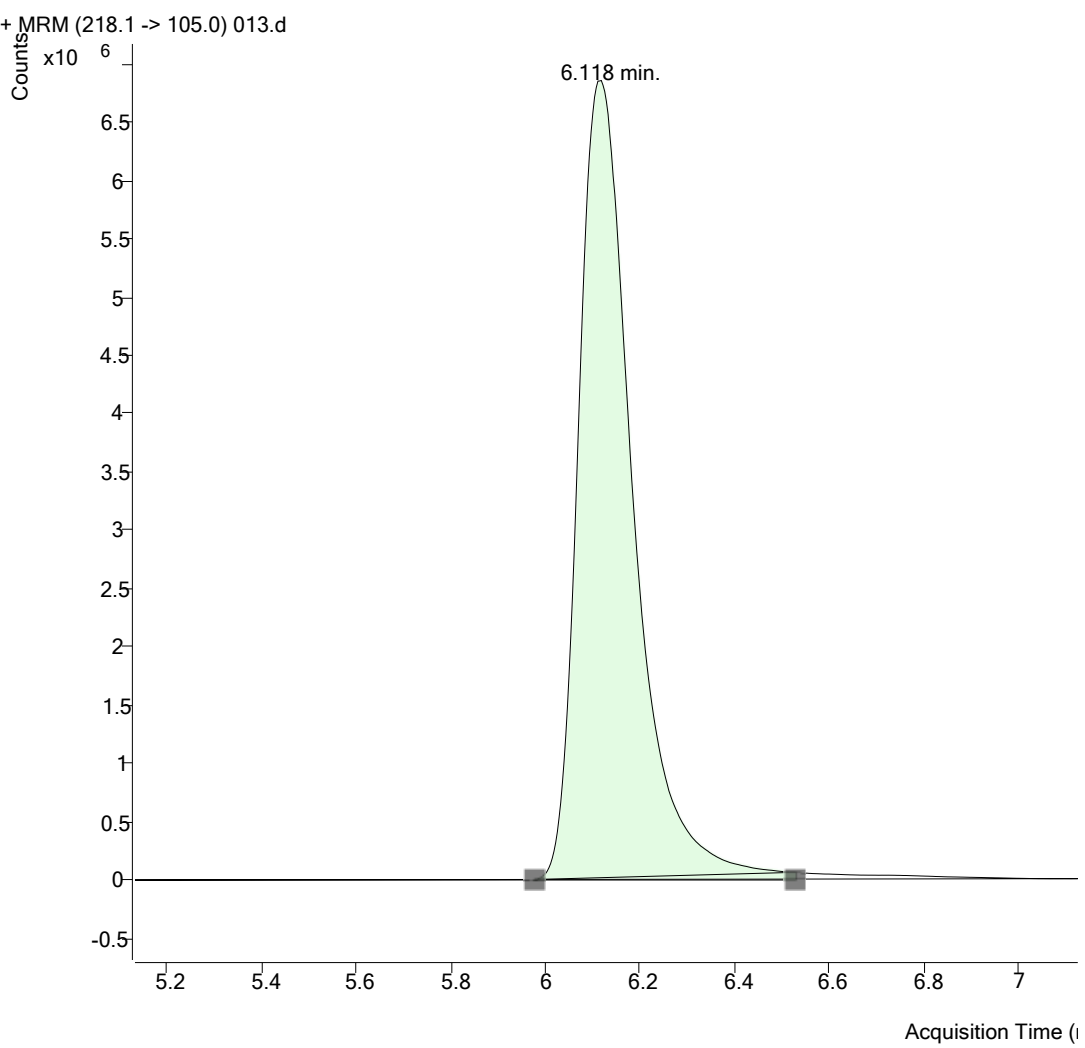

Chromatogram of a $264 \mathrm{ng} / \mathrm{ml}$ pymetrozine standard (218.1---105.0); quantifier. 


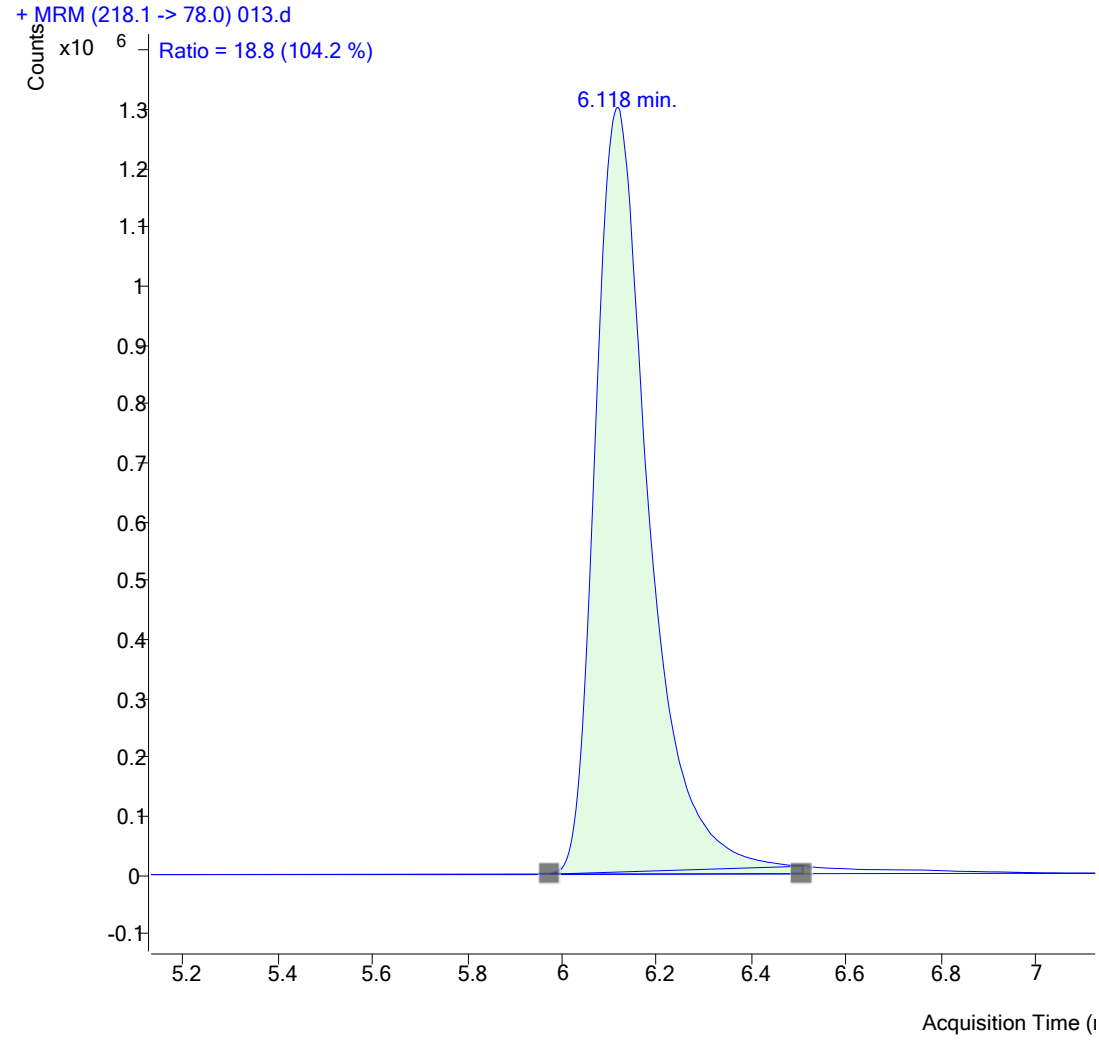

Chromatogram of a $264 \mathrm{ng} / \mathrm{ml}$ pymetrozine standard (218.1---78.0); qualifier.

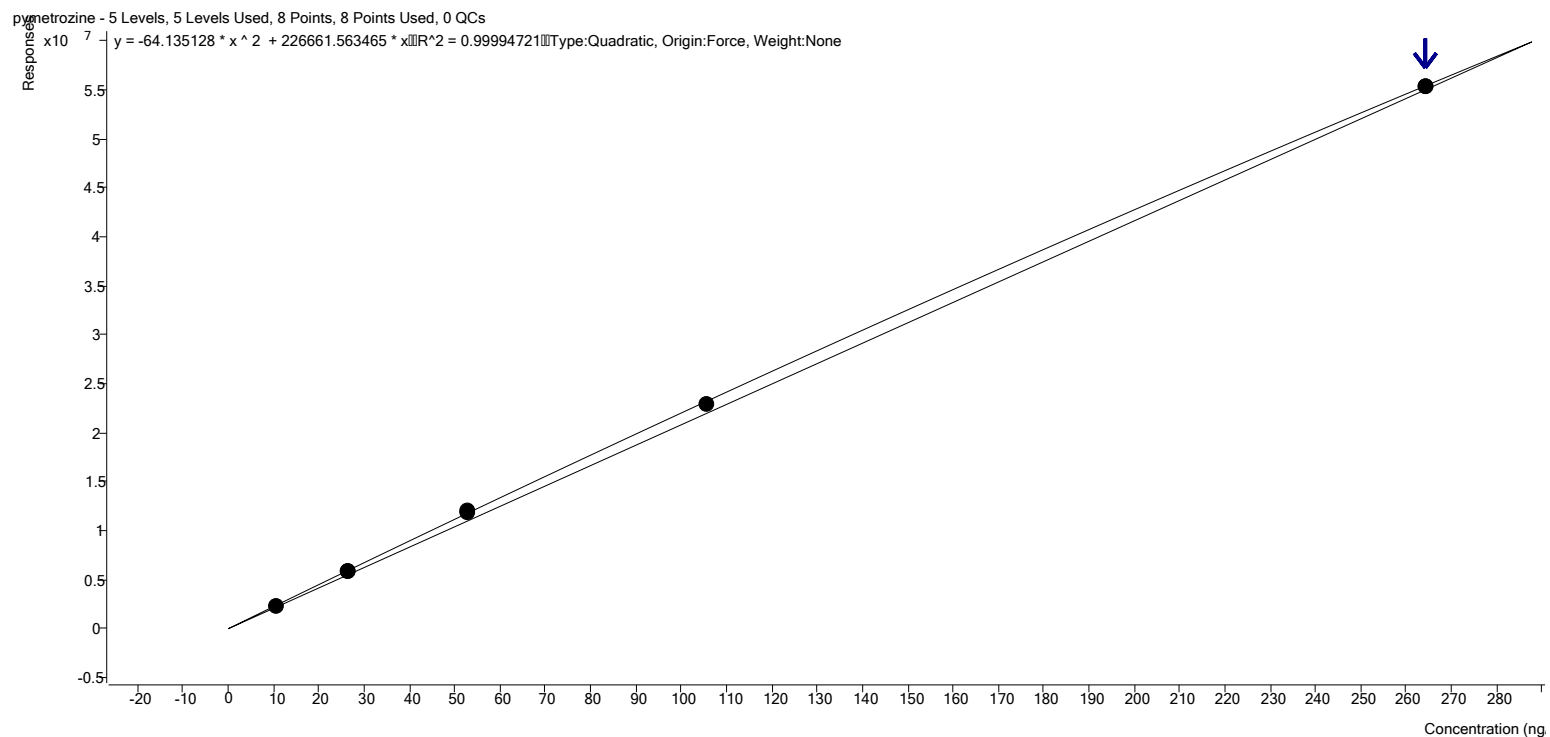

Calibration curve of pymetrozine. 


\section{Standard E-and Z-dimethomorph}

The total concentration of the standard dimethomorph is $250 \mathrm{ng} / \mathrm{ml:} 83.33 \mathrm{ng} / \mathrm{ml}$ E-dimethomorph and $166.66 \mathrm{ng} / \mathrm{ml}$ Z-dimethomorph.

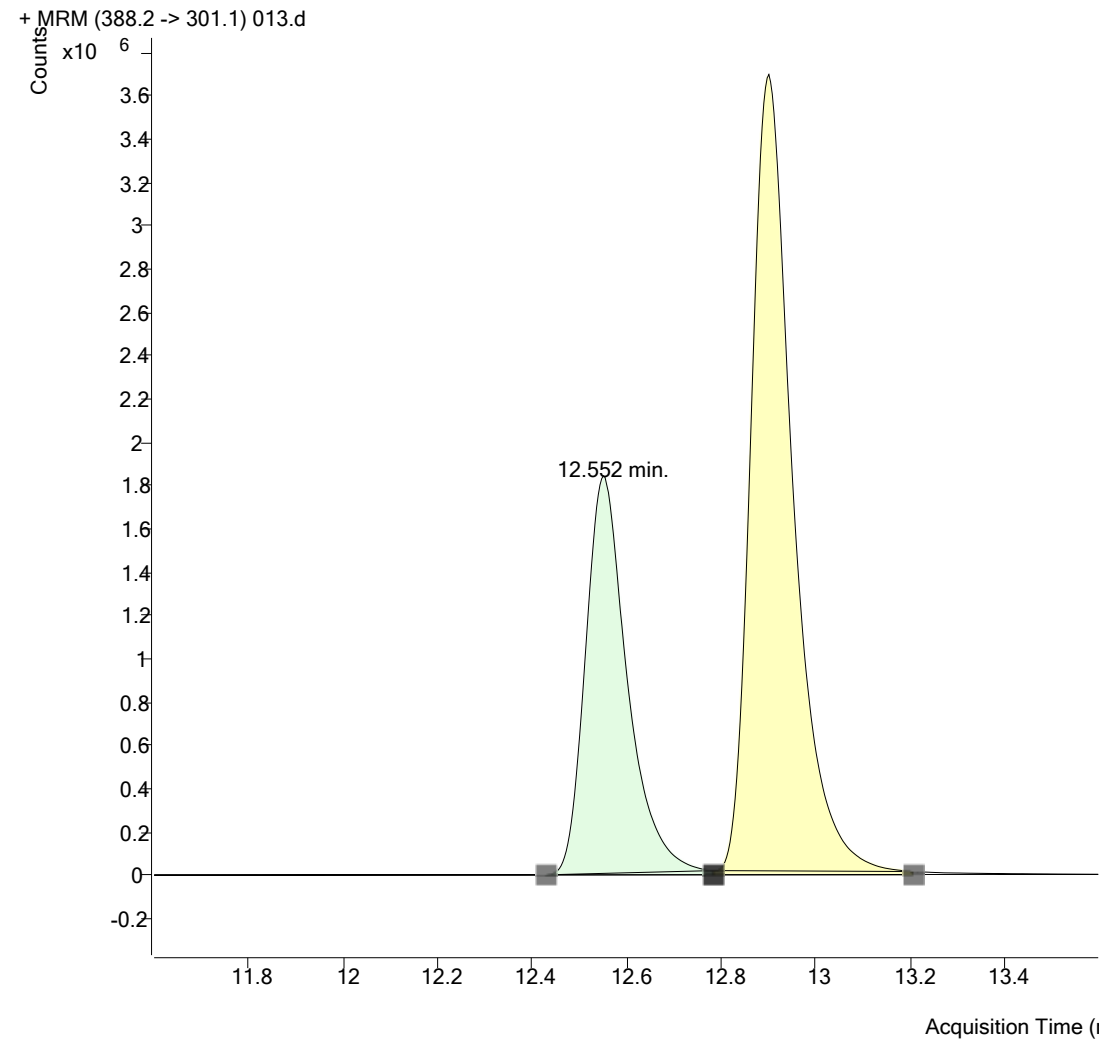

Chromatogram of a $83.33 \mathrm{ng} / \mathrm{ml}$ E-dimethomorph standard (388.2---301.1); quantifier.

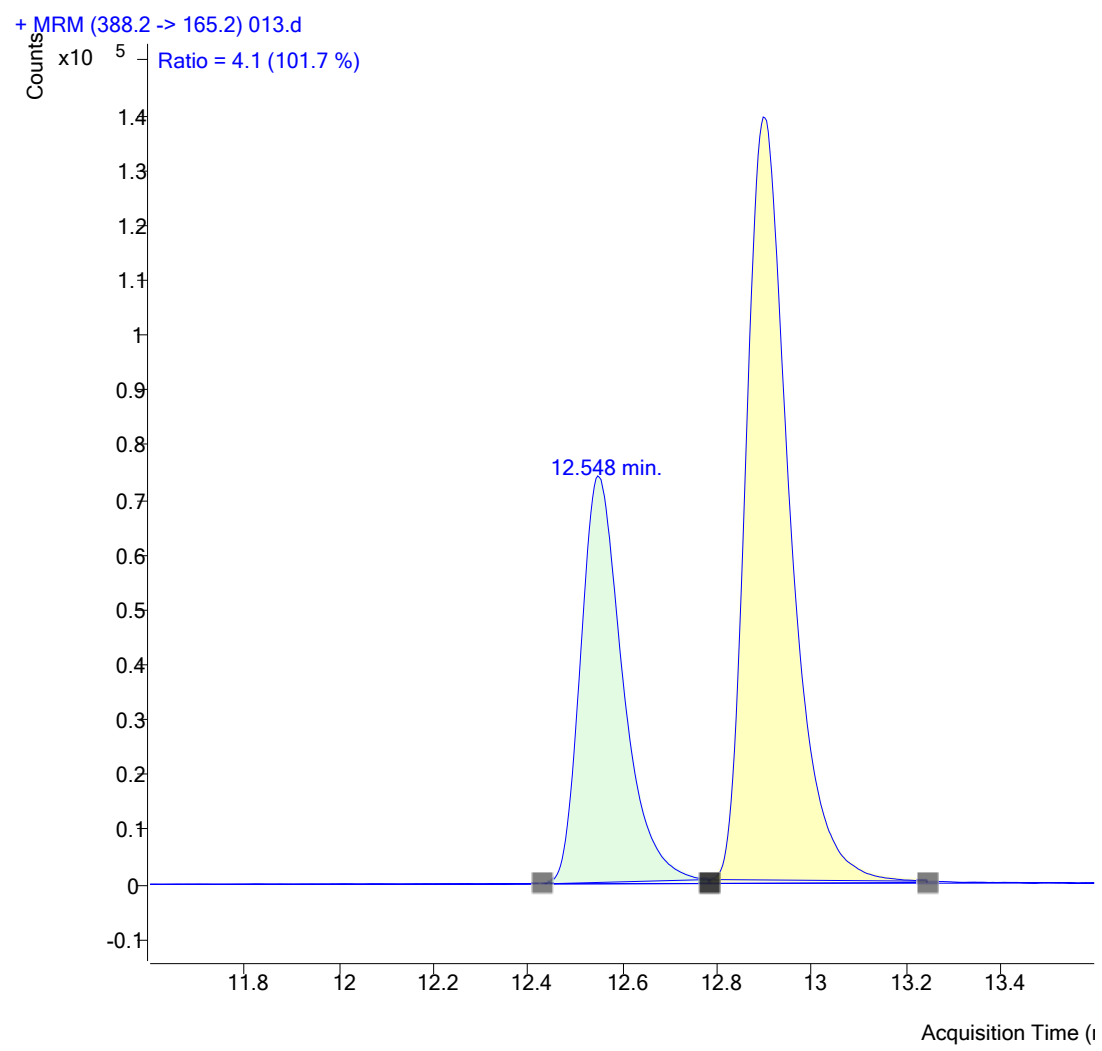

Chromatogram of a $83.33 \mathrm{ng} / \mathrm{ml}$ E-dimethomorph standard (388.2---165.2); qualifier. 


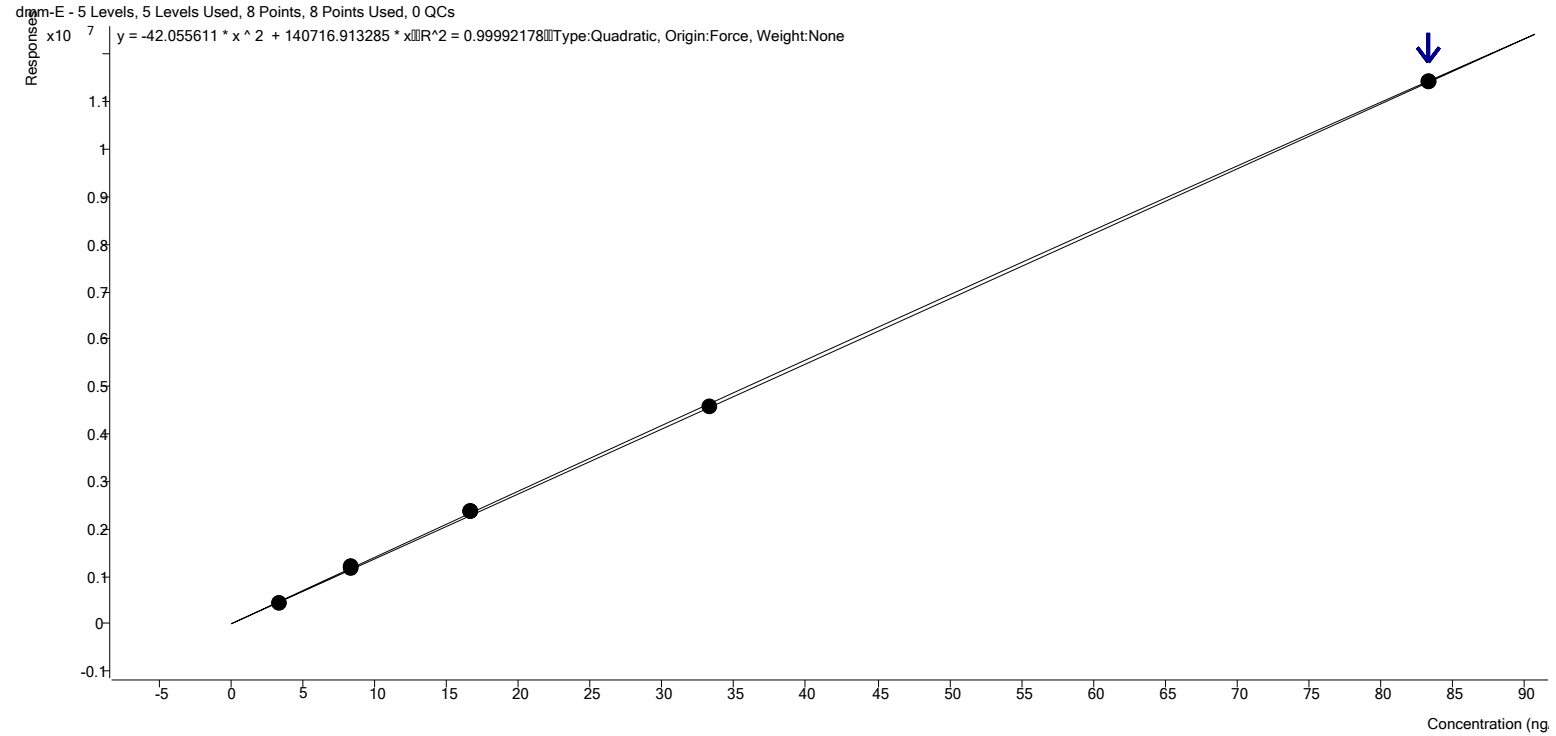

Calibration curve of E-dimethomorph.

\section{Z-dimethomorph}

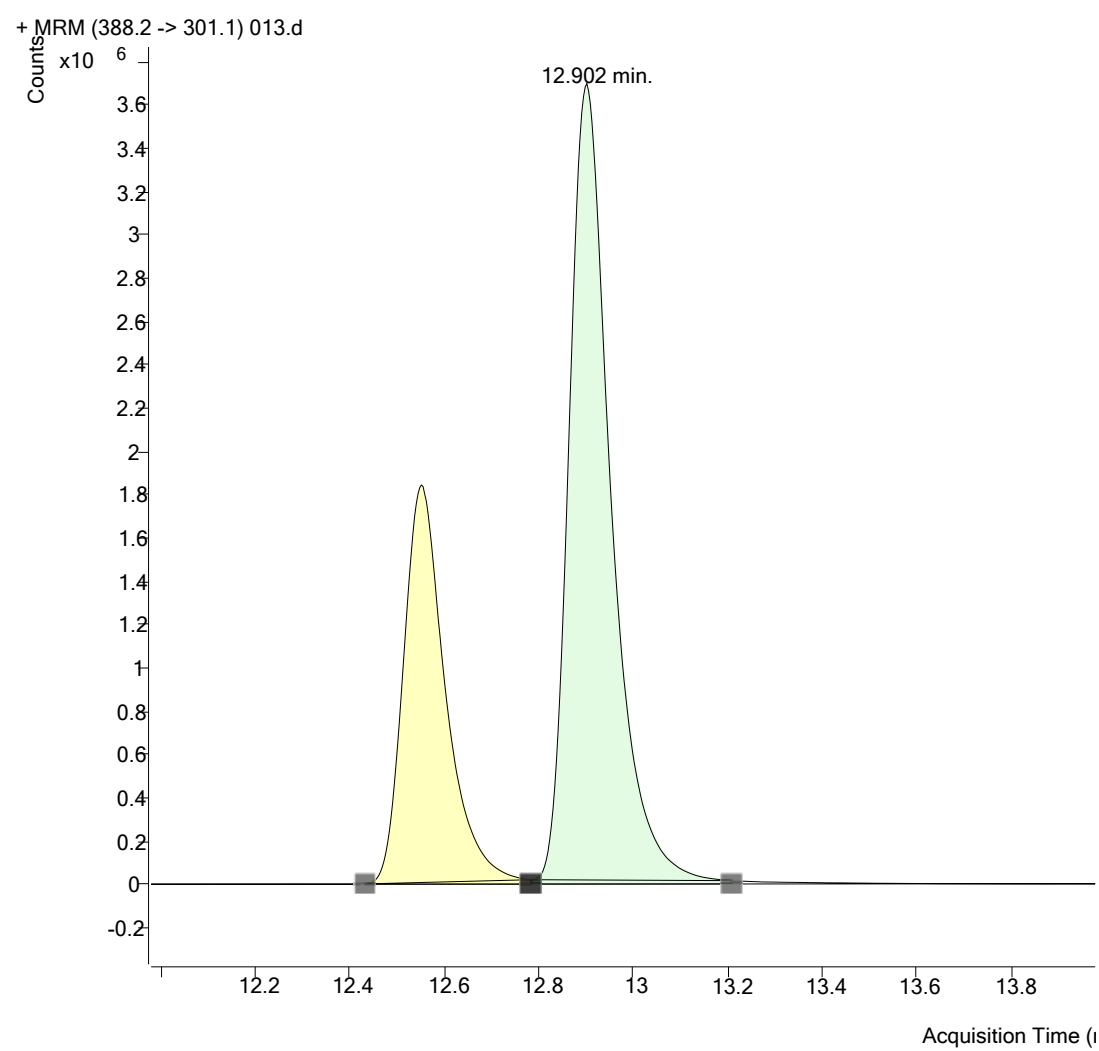

Chromatogram of a $166.66 \mathrm{ng} / \mathrm{ml}$ Z-dimethomorph standard (388.2---301.1); quantifier. 


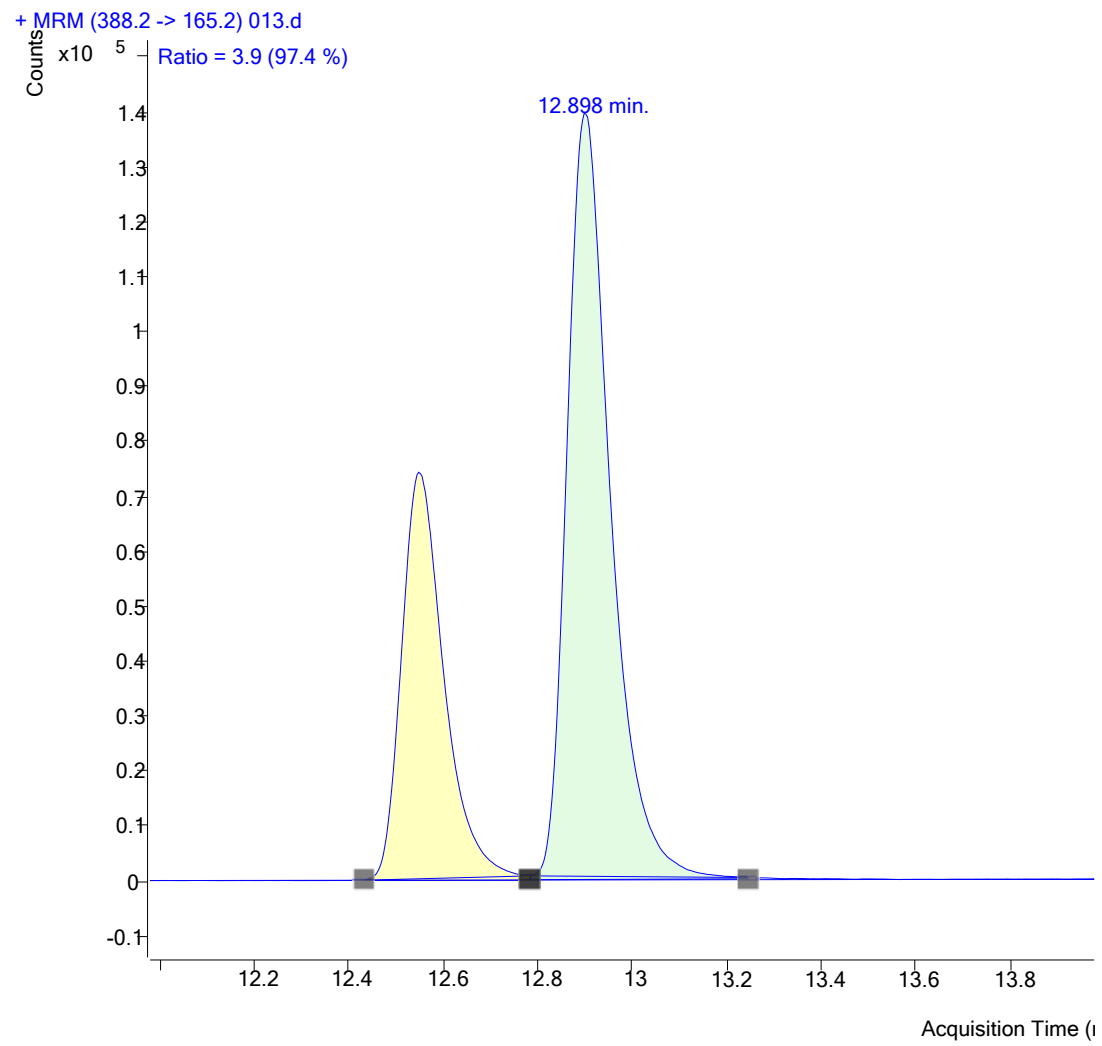

Chromatogram of a $166.66 \mathrm{ng} / \mathrm{ml}$ Z-dimethomorph standard (388.2---301.1); qualifier.

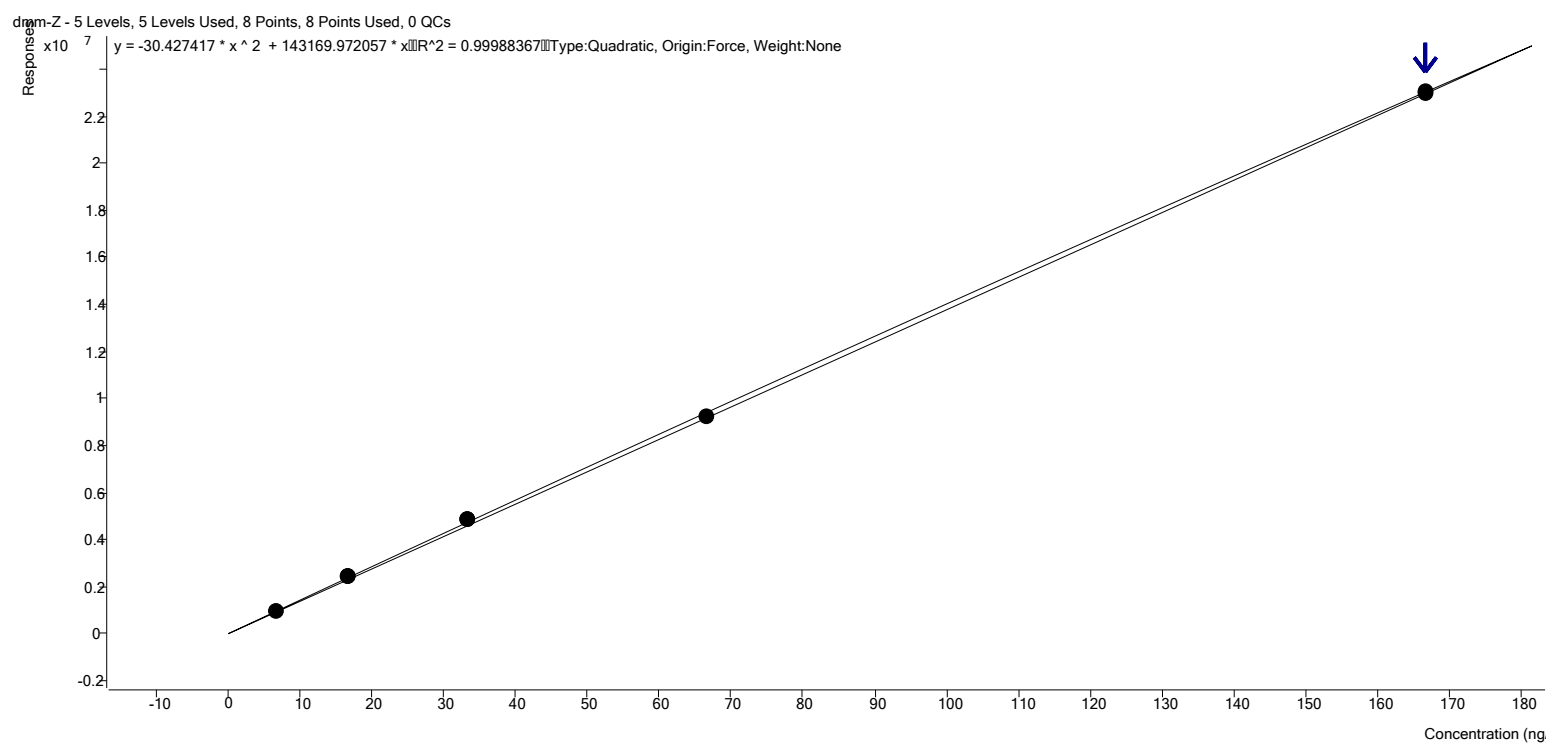

Calibration curve of Z-dimethomorph. 


\section{Chromatogram of a sample}

\section{Pymetrozine: measured concentration in LC-sample: $254.93 \mathrm{ng} / \mathrm{ml}$}

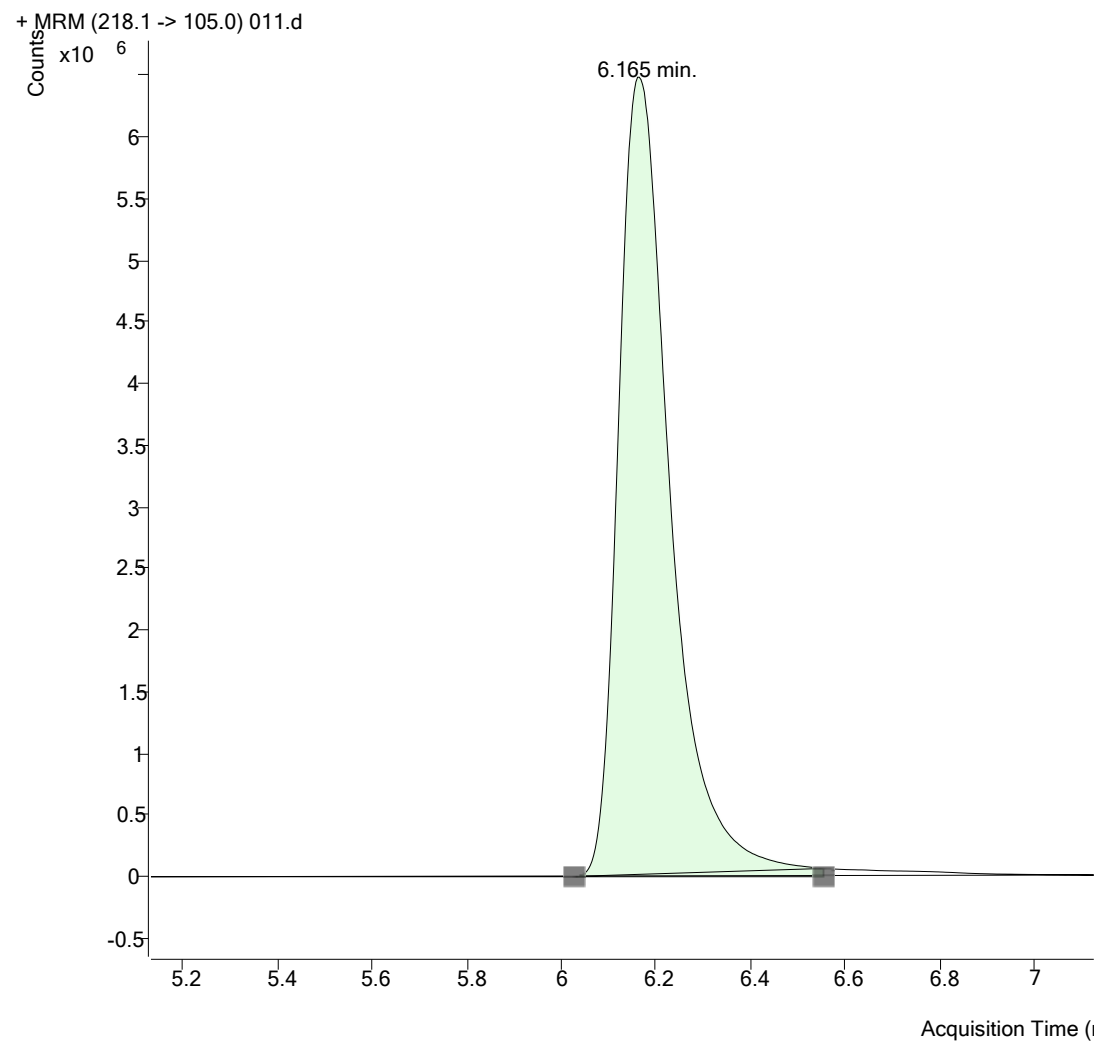

Chromatogram of sample D35 (10 times diluted) measured concentration $254.93 \mathrm{ng} / \mathrm{ml}$ pymetrozine standard (218.1---105.0); quantifier.

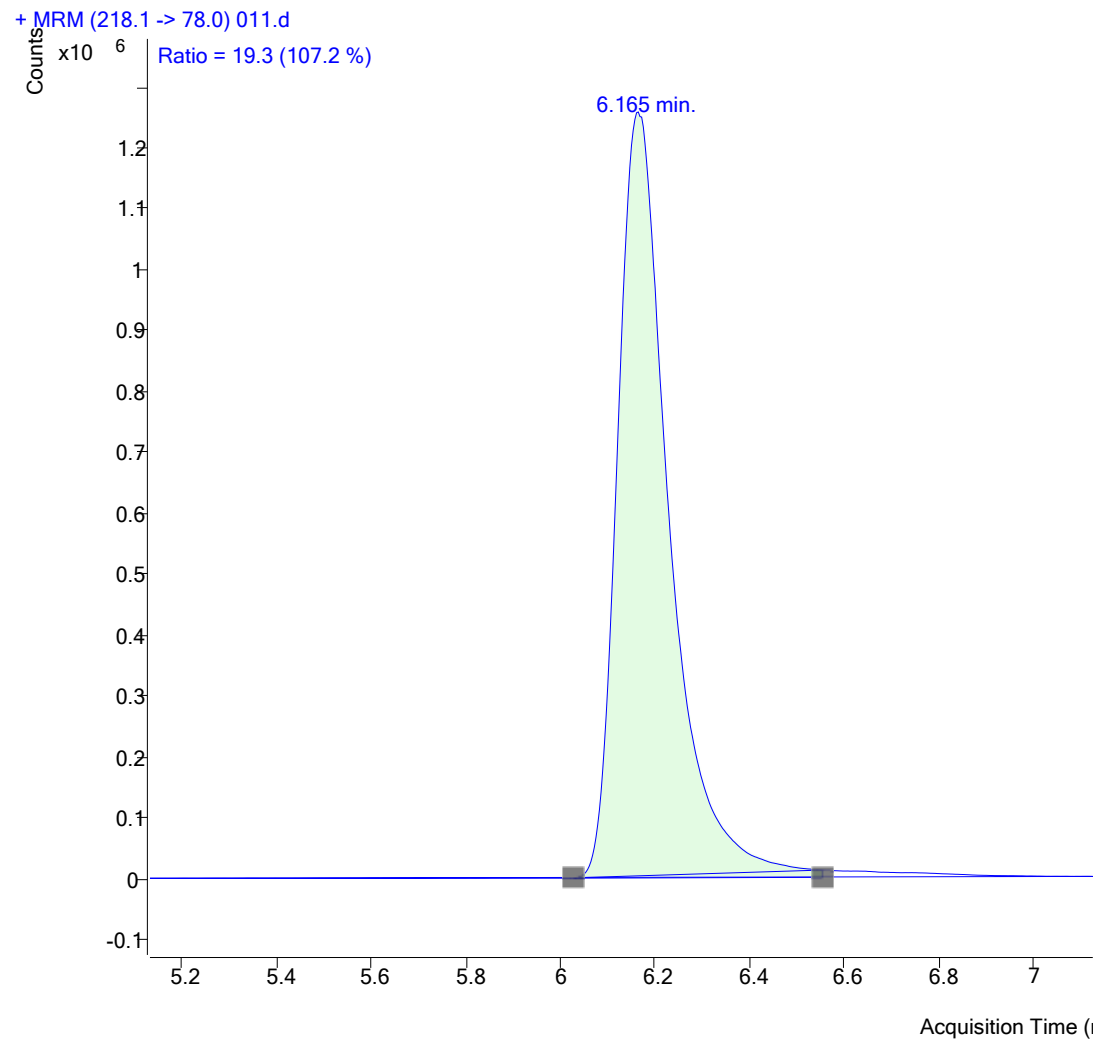

Chromatogram of sample D35 (10 times diluted) measured concentration $254.93 \mathrm{ng} / \mathrm{ml}$ pymetrozine standard (218.1---78.0); quantifier. 


\section{Chromatogram of a sample}

Dimethomorph: measured concentration in LC-sample (extract): $\mathbf{1 6 . 5 6 6 3 ~} \mathrm{ng} / \mathrm{ml} \mathrm{E}-$ dimethomorph and $29.3448 \mathrm{ng} / \mathrm{ml}$ Z-methomorph.

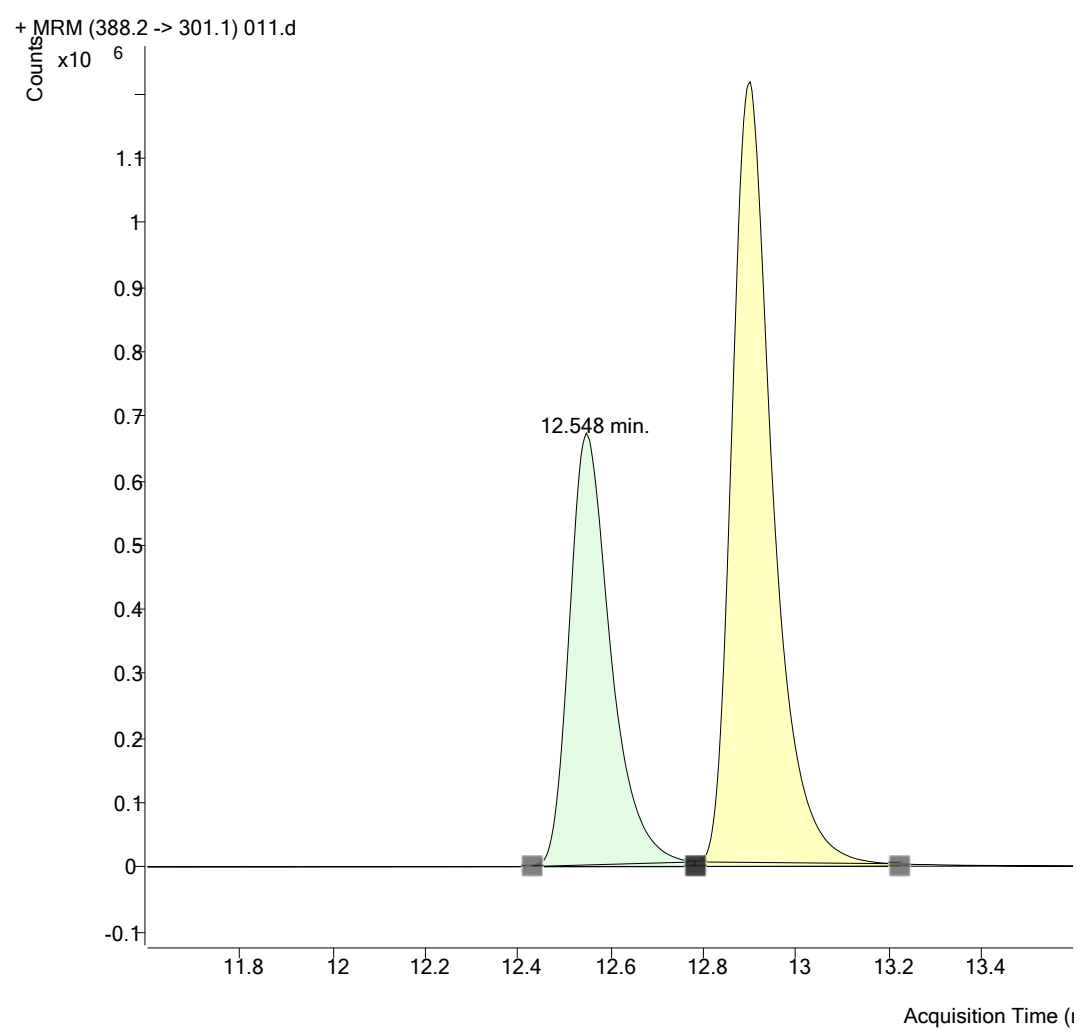

Chromatogram of sample D35 (10 times diluted) measured concentration $16.5663 \mathrm{ng} / \mathrm{ml}$ Edimethomorph standard (388.1---301.1); qualifier.

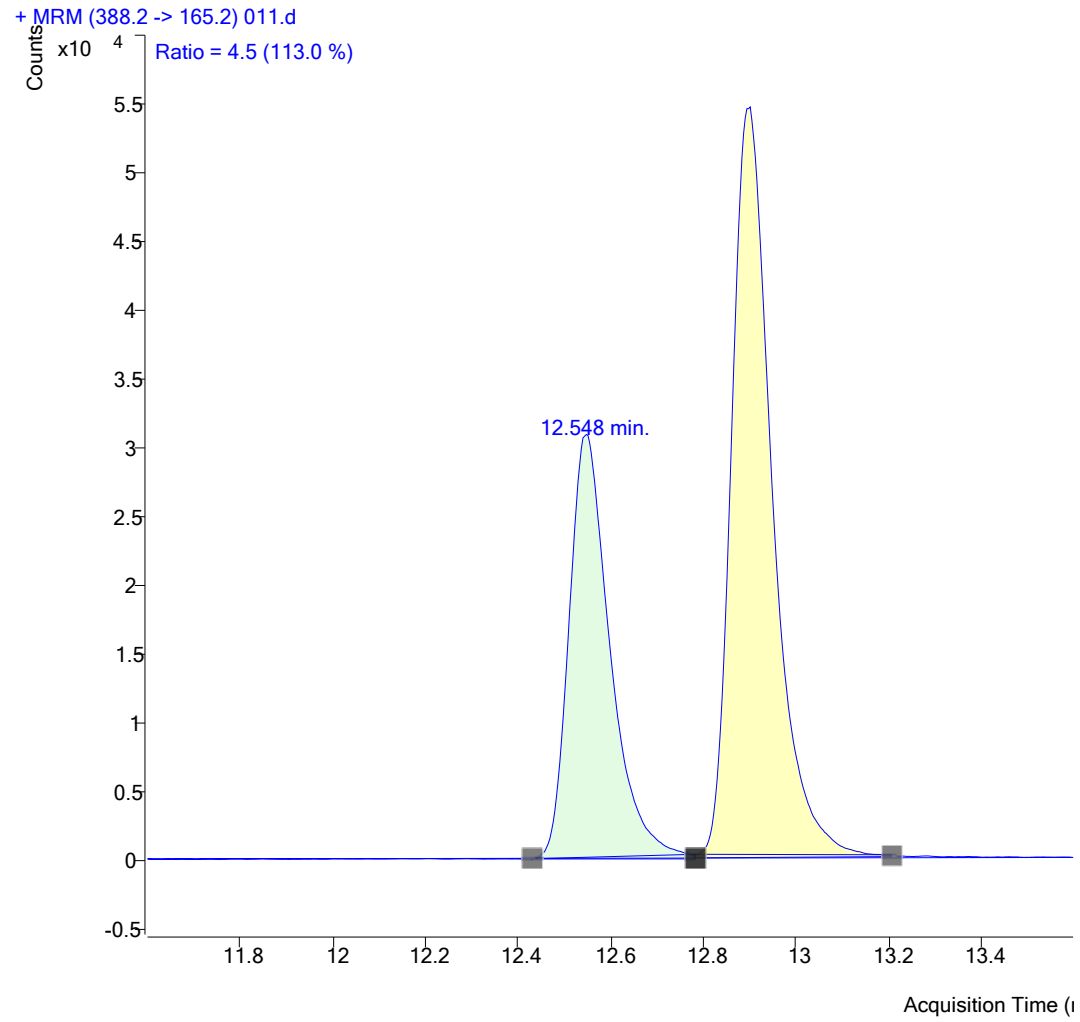

Chromatogram of sample D35 (10 times diluted) measured concentration $16.5663 \mathrm{ng} / \mathrm{ml}$ Edimethomorph standard (388.1---165.2); quantifier. 


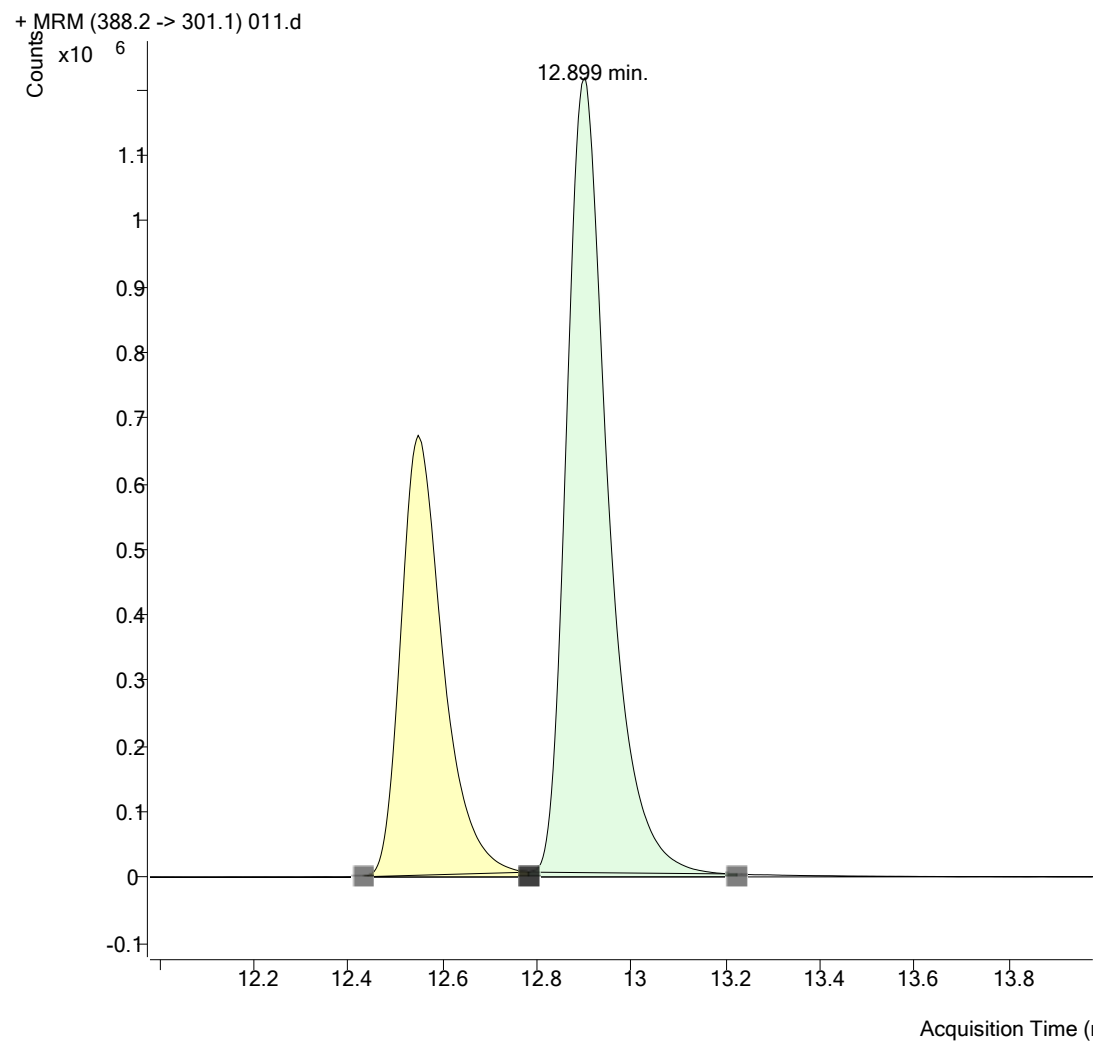

Chromatogram of sample D35 (10 times diluted) measured concentration $29.3448 \mathrm{ng} / \mathrm{ml} \mathrm{Z-}$ dimethomorph standard (388.1---301.1); quantifier.

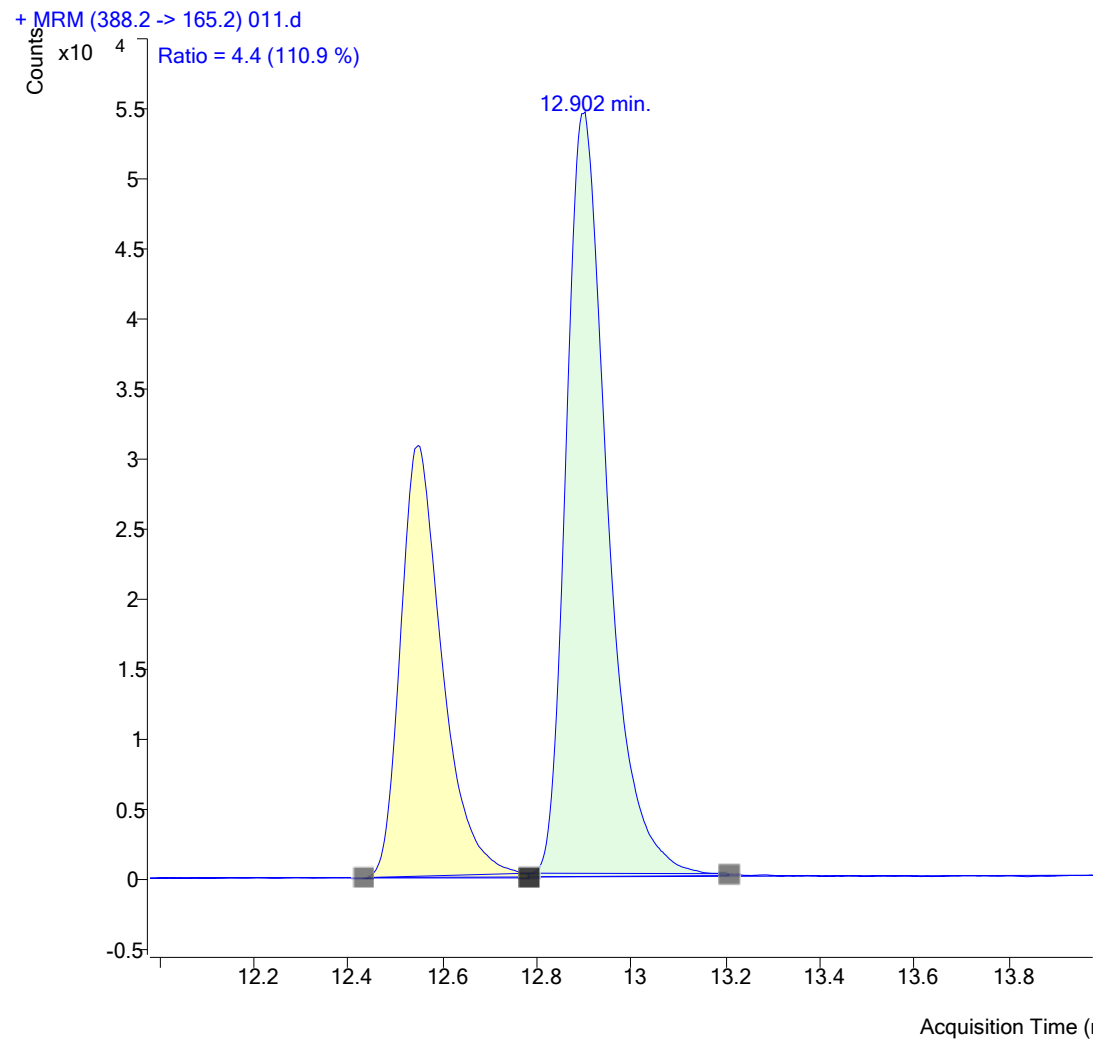

Chromatogram of sample D35 (10 times diluted) measured concentration $29.3448 \mathrm{ng} / \mathrm{ml} \mathrm{Z-}$ dimethomorph standard (388.1---165.2); qualifier. 


\section{Annex 2 Detailed results of batch sorption experiments with clean stonewool}

Table A2-1 Results of sorption experiments with pymetrozine and Grotop stonewool. The buffer was added to samples 1-3 and not to sample 4.

\begin{tabular}{llcccc} 
& \multicolumn{5}{c}{$\mathrm{nr}$ of sample } \\
\cline { 2 - 5 } mass of dry stonewool $(\mathrm{g})$ & 1 & 2 & 3 & 4 \\
\hline volume of $\mathrm{Ca}\left(\mathrm{NO}_{3}\right)_{2}$ solution during experiment $(\mathrm{mL})$ & 3.41 & 3.21 & 3.29 & 3.44 \\
\hline concentration $(\mu \mathrm{g} / \mathrm{L})$ & initial & 78 & 76 & 69 & 68 \\
\cline { 2 - 6 } & final & 71 & 71 & 80 & 79 \\
\hline mass $(\mu \mathrm{g})$ & in Ca $\left(\mathrm{NO}_{3}\right)_{2}$ solution just before extraction with & 12 & 72 & 79 & 76 \\
& methanol & 1.68 & 1.77 & 1.92 & 1.69 \\
\cline { 2 - 6 } & extracted with methanol & 1.67 & 1.83 & 1.97 & 1.80 \\
\hline $\begin{array}{l}\text { sorption coefficient } K \\
\text { (L/kg) based on }\end{array}$ & difference between initial and final concentrations & -0.13 & -0.21 & 0.21 & 0.70 \\
\cline { 2 - 6 } recovery $(\%)$ & methanol extraction & -0.05 & 0.29 & 0.21 & 0.43 \\
\hline
\end{tabular}

Table A2-2 Results of sorption experiments with pymetrozine and Cultilene stonewool. The buffer was added to samples 1-3 and not to sample 4.

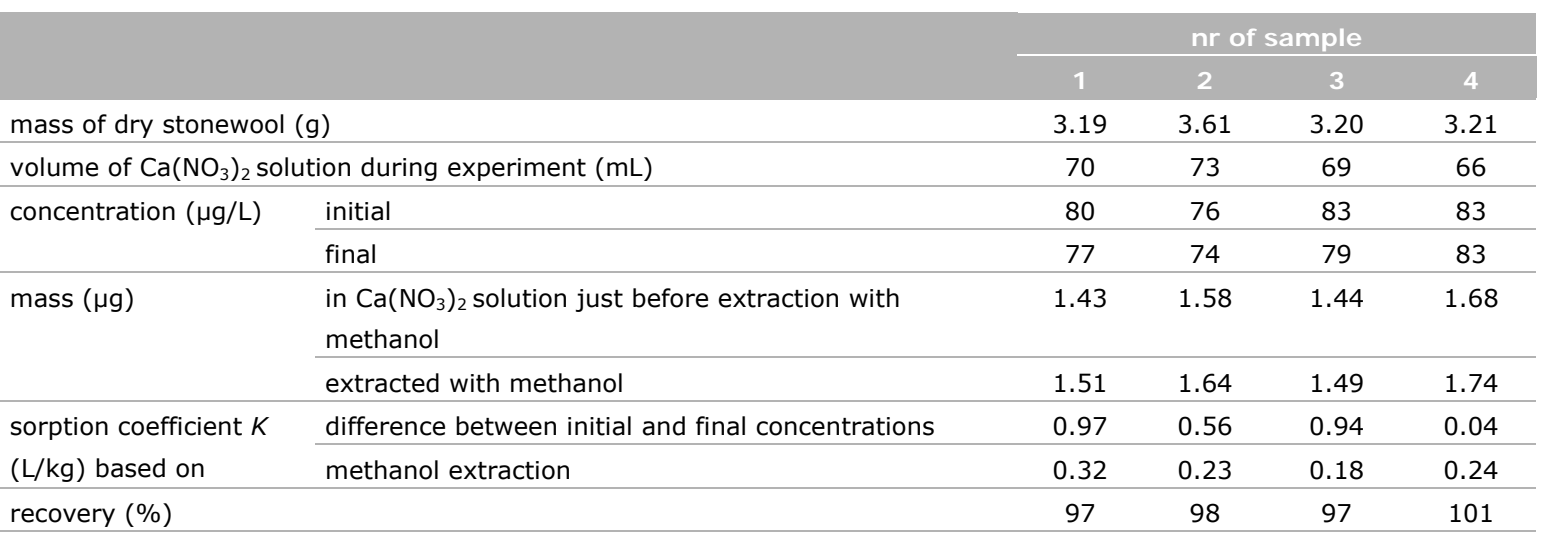

Table A2-3 Results of sorption experiments with E-dimethomorph and Grotop stonewool. The buffer was added to samples 1-3 and not to sample 4.

\begin{tabular}{|c|c|c|c|c|c|}
\hline & & \multicolumn{4}{|c|}{ nr of sample } \\
\hline & & 1 & 2 & 3 & 4 \\
\hline \multicolumn{2}{|c|}{ mass of dry stonewool $(\mathrm{g})$} & 3.01 & 3.57 & 3.10 & 3.23 \\
\hline \multicolumn{2}{|c|}{ volume of $\mathrm{Ca}\left(\mathrm{NO}_{3}\right)_{2}$ solution during experiment $(\mathrm{mL})$} & 66 & 65 & 71 & 68 \\
\hline \multirow[t]{2}{*}{ concentration $(\mu \mathrm{g} / \mathrm{L})$} & initial & 22 & 19 & 21 & 19 \\
\hline & final & 21 & 18 & 20 & 19 \\
\hline \multirow[t]{2}{*}{ mass $(\mu g)$} & $\begin{array}{l}\text { in } \mathrm{Ca}\left(\mathrm{NO}_{3}\right)_{2} \text { solution just before extraction with } \\
\text { methanol }\end{array}$ & 0.35 & 0.37 & 0.41 & 0.39 \\
\hline & extracted with methanol & 0.41 & 0.50 & 0.48 & 0.45 \\
\hline \multirow{2}{*}{$\begin{array}{l}\text { sorption coefficient } K \\
(\mathrm{~L} / \mathrm{kg}) \text { based on }\end{array}$} & difference between initial and final concentrations & 0.47 & 0.43 & 0.50 & 0.09 \\
\hline & methanol extraction & 0.85 & 1.93 & 1.09 & 1.07 \\
\hline \multicolumn{2}{|l|}{ recovery (\%) } & 102 & 108 & 103 & 105 \\
\hline
\end{tabular}


Table A2-4 Results of sorption experiments with E-dimethomorph and Cultilene stonewool. The buffer was added to samples 1-3 and not to sample 4.

\begin{tabular}{|c|c|c|c|c|c|}
\hline & & \multicolumn{4}{|c|}{ nr of sample } \\
\hline & & 1 & 2 & 3 & 4 \\
\hline \multicolumn{2}{|c|}{ mass of dry stonewool $(\mathrm{g})$} & 3.18 & 3.53 & 3.73 & 3.31 \\
\hline \multirow[t]{2}{*}{ concentration $(\mu \mathrm{g} / \mathrm{L})$} & initial & 18 & 19 & 20 & 21 \\
\hline & final & 18 & 19 & 21 & \\
\hline mass $(\mu \mathrm{g})$ & extracted with methanol & 0.44 & 0.45 & 0.50 & \\
\hline \multirow{2}{*}{$\begin{array}{l}\text { sorption coefficient } K \\
(\mathrm{~L} / \mathrm{kg}) \text { based on }\end{array}$} & difference between initial and final concentrations & -0.34 & -0.25 & -0.62 & \\
\hline & methanol extraction & 1.16 & 0.72 & 1.13 & \\
\hline
\end{tabular}

Table A2-5 Results of sorption experiments with Z-dimethomorph and Grotop stonewool. The buffer was added to samples 1-3 and not to sample 4.

\begin{tabular}{|c|c|c|c|c|c|}
\hline & & \multicolumn{4}{|c|}{ nr of sample } \\
\hline & & 1 & 2 & 3 & 4 \\
\hline \multicolumn{2}{|c|}{ mass of dry stonewool $(\mathrm{g})$} & 3.01 & 3.57 & 3.10 & 3.23 \\
\hline \multirow[t]{2}{*}{ concentration $(\mu \mathrm{g} / \mathrm{L})$} & initial & 56 & 49 & 54 & 49 \\
\hline & final & 51 & 43 & 49 & 45 \\
\hline mass $(\mu \mathrm{g})$ & extracted with methanol & 1.00 & 1.15 & 1.26 & 1.12 \\
\hline \multirow{2}{*}{$\begin{array}{l}\text { sorption coefficient } K \\
(\mathrm{~L} / \mathrm{kg}) \text { based on }\end{array}$} & difference between initial and final concentrations & 2.20 & 2.24 & 2.54 & 2.25 \\
\hline & methanol extraction & 0.99 & 1.74 & 1.78 & 1.42 \\
\hline \multicolumn{2}{|l|}{ recovery (\%) } & 95 & 98 & 97 & 96 \\
\hline
\end{tabular}

Table A2-6 Results of sorption experiments with Z-dimethomorph and Cultilene stonewool. The buffer was added to samples 1-3 and not to sample 4.

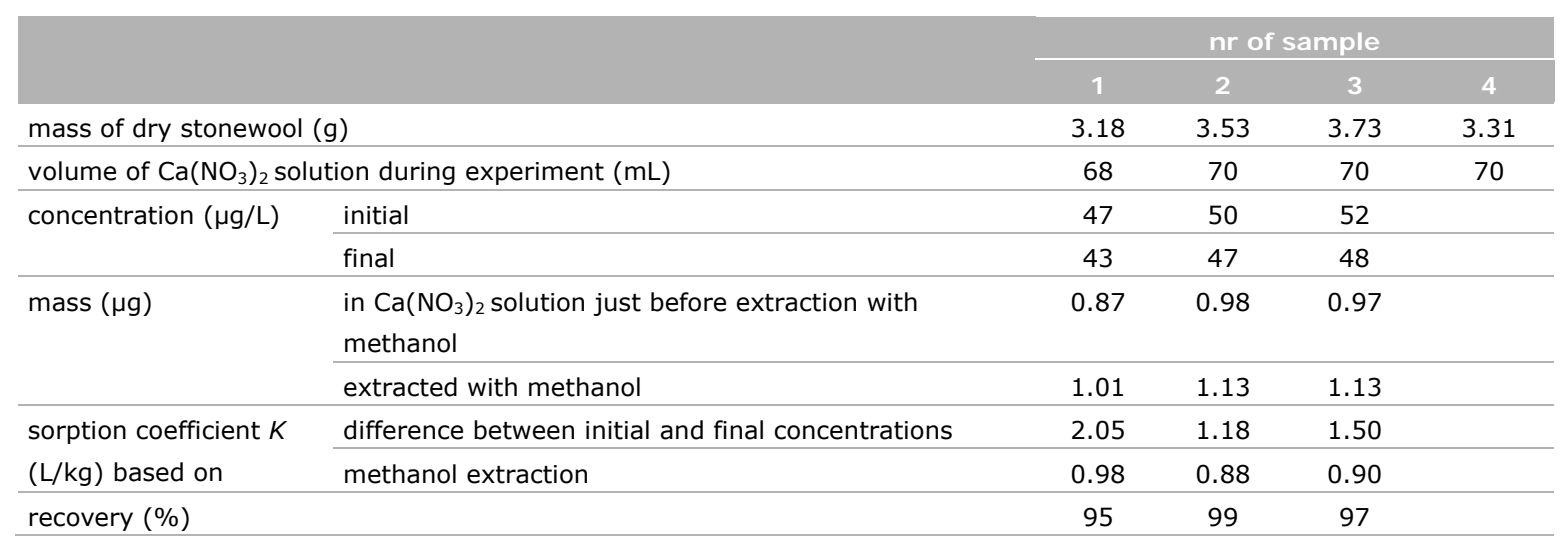




\section{Annex 3 Detailed results of batch sorption experiments with pipe materials and stonewool foil}

Table A3-1 Results of sorption experiments with pymetrozine and TP material.

\begin{tabular}{|c|c|c|c|c|c|}
\hline & & \multicolumn{4}{|c|}{ nr of sample } \\
\hline & & 1 & 2 & 3 & 4 \\
\hline \multicolumn{2}{|l|}{ mass of TP material $(\mathrm{g})$} & 2.62 & 2.71 & 2.56 & 2.71 \\
\hline \multicolumn{2}{|c|}{ volume of $\mathrm{Ca}\left(\mathrm{NO}_{3}\right)_{2}$ solution during experiment $(\mathrm{mL})$} & 4.98 & 5.00 & 5.00 & 4.99 \\
\hline \multirow[t]{2}{*}{ concentration $(\mu \mathrm{g} / \mathrm{L})$} & initial & 102 & 102 & 102 & 102 \\
\hline & final & 104 & 105 & 112 & 107 \\
\hline \multirow[t]{2}{*}{ mass (ng) } & $\begin{array}{l}\text { in } \mathrm{Ca}\left(\mathrm{NO}_{3}\right)_{2} \text { solution just before extraction with } \\
\text { methanol }\end{array}$ & 47 & 46 & 43 & 41 \\
\hline & extracted with methanol & 49 & 50 & 40 & 41 \\
\hline \multirow{2}{*}{$\begin{array}{l}\text { sorption coefficient } K \\
(\mathrm{~L} / \mathrm{kg}) \text { based on }\end{array}$} & difference between initial and final concentrations & -0.04 & -0.05 & -0.17 & -0.09 \\
\hline & methanol extraction & 0.01 & 0.01 & -0.01 & 0.00 \\
\hline \multicolumn{2}{|l|}{ recovery (\%) } & 102 & 103 & 109 & 105 \\
\hline
\end{tabular}

Table A3-2 Results of sorption experiments with pymetrozine and DP material.

\begin{tabular}{llcccc} 
& \multicolumn{5}{c}{ nr of sample } \\
\cline { 2 - 5 } mass of $\mathrm{DP}$ material $(\mathrm{g})$ & 1 & 2 & 3 & 4 \\
\hline volume of $\mathrm{Ca}\left(\mathrm{NO}_{3}\right)_{2}$ solution during experiment $(\mathrm{mL})$ & 2.01 & 2.00 & 2.01 & 2.03 \\
\hline concentration $(\mu \mathrm{g} / \mathrm{L})$ & initial & 5.00 & 4.99 & 4.85 & 4.99 \\
\cline { 2 - 6 } & final & 102 & 102 & 102 & 102 \\
\hline mass $(\mathrm{ng})$ & in $\mathrm{Ca}\left(\mathrm{NO}_{3}\right)_{2}$ solution just before extraction with & 103 & 105 & 103 & 105 \\
& methanol & 54 & 78 & 75 & 52 \\
\cline { 2 - 6 } & extracted with methanol & 61 & 86 & 74 & 52 \\
\hline sorption coefficient $K$ & difference between initial and final concentrations & -0.02 & -0.07 & -0.02 & -0.08 \\
\cline { 2 - 6 }$(\mathrm{L} / \mathrm{kg})$ based on & methanol extraction & 0.03 & 0.04 & -0.01 & 0.00 \\
\hline recovery $(\%)$ & & 102 & 105 & 101 & 104 \\
\hline
\end{tabular}

Table A3-3 Results of sorption experiments with pymetrozine and SF material.

\begin{tabular}{|c|c|c|c|c|c|}
\hline & & \multicolumn{4}{|c|}{ nr of sample } \\
\hline & & 1 & 2 & 3 & 4 \\
\hline \multicolumn{2}{|l|}{ mass of SF material $(\mathrm{g})$} & 1.05 & 1.01 & 1.07 & 1.02 \\
\hline \multicolumn{2}{|c|}{ volume of $\mathrm{Ca}\left(\mathrm{NO}_{3}\right)_{2}$ solution during experiment $(\mathrm{mL})$} & 8.05 & 8.00 & 8.02 & 8.04 \\
\hline \multirow[t]{2}{*}{ concentration $(\mu \mathrm{g} / \mathrm{L})$} & initial & 104 & 104 & 104 & 104 \\
\hline & final & 103 & 108 & 106 & 110 \\
\hline \multirow[t]{2}{*}{ mass (ng) } & $\begin{array}{l}\text { in } \mathrm{Ca}\left(\mathrm{NO}_{3}\right)_{2} \text { solution just before extraction with } \\
\text { methanol }\end{array}$ & 227 & 161 & 171 & 152 \\
\hline & extracted with methanol & 204 & 162 & 152 & 155 \\
\hline \multirow{2}{*}{$\begin{array}{l}\text { sorption coefficient } K \\
(\mathrm{~L} / \mathrm{kg}) \text { based on }\end{array}$} & difference between initial and final concentrations & 0.11 & -0.24 & -0.12 & -0.40 \\
\hline & methanol extraction & -0.22 & 0.00 & -0.17 & 0.03 \\
\hline \multicolumn{2}{|l|}{ recovery (\%) } & 96 & 103 & 99 & 106 \\
\hline
\end{tabular}


Table A3-4 Results of sorption experiments with E-dimethomorph and TP material.

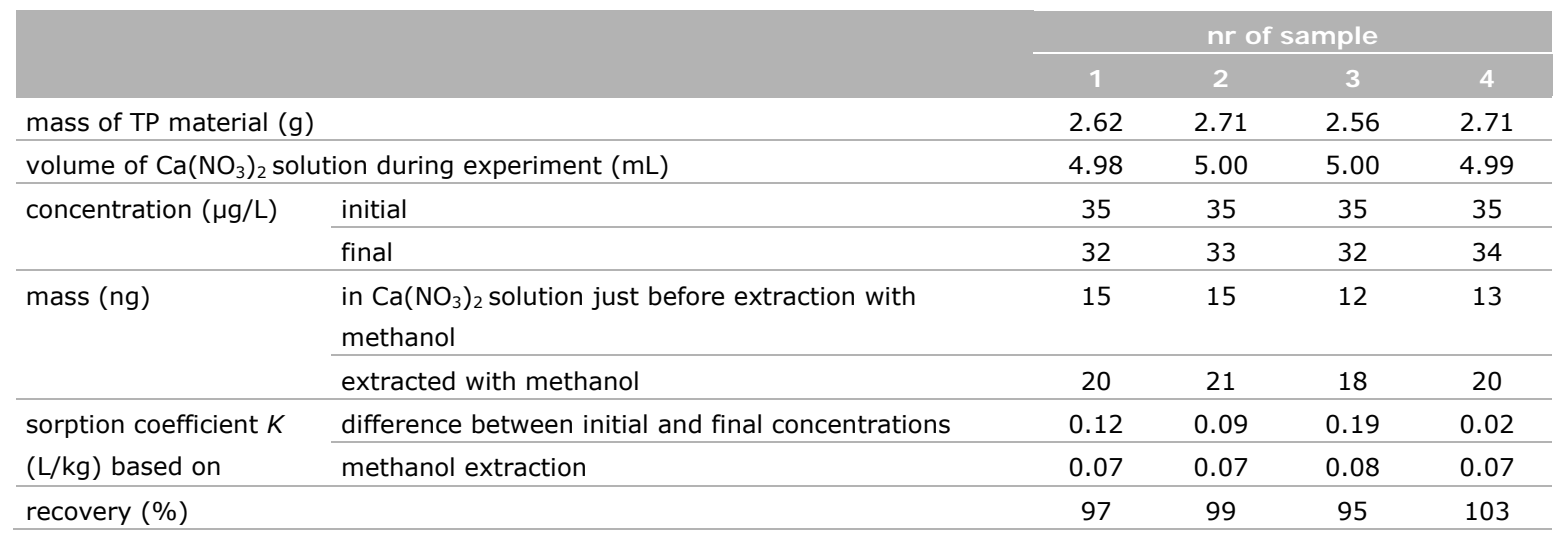

Table A3-5 Results of sorption experiments with E-dimethomorph and DP material.

\begin{tabular}{|c|c|c|c|c|c|}
\hline & & \multicolumn{4}{|c|}{ nr of sample } \\
\hline & & 1 & 2 & 3 & 4 \\
\hline \multicolumn{2}{|l|}{ mass of DP material $(\mathrm{g})$} & 2.01 & 2.00 & 2.01 & 2.03 \\
\hline \multirow[t]{2}{*}{ concentration $(\mu \mathrm{g} / \mathrm{L})$} & initial & 35 & 35 & 35 & 35 \\
\hline & final & 32 & 31 & 30 & 31 \\
\hline mass (ng) & extracted with methanol & 27 & 33 & 31 & 23 \\
\hline \multirow{2}{*}{$\begin{array}{l}\text { sorption coefficient } K \\
(\mathrm{~L} / \mathrm{kg}) \text { based on }\end{array}$} & difference between initial and final concentrations & 0.17 & 0.28 & 0.34 & 0.25 \\
\hline & methanol extraction & 0.15 & 0.16 & 0.14 & 0.11 \\
\hline
\end{tabular}

Table A3-6 Results of sorption experiments with E-dimethomorph and SF material.

\begin{tabular}{|c|c|c|c|c|c|}
\hline & & \multicolumn{4}{|c|}{ nr of sample } \\
\hline \multicolumn{2}{|l|}{ mass of SF material $(\mathrm{g})$} & 1.05 & 1.01 & 1.07 & 1.02 \\
\hline \multirow[t]{2}{*}{ concentration $(\mu \mathrm{g} / \mathrm{L})$} & initial & 39 & 39 & 39 & 39 \\
\hline & final & 32 & 32 & 33 & 33 \\
\hline mass (ng) & extracted with methanol & 74 & 55 & 58 & 52 \\
\hline \multirow{2}{*}{$\begin{array}{l}\text { sorption coefficient } K \\
(\mathrm{~L} / \mathrm{kg}) \text { based on }\end{array}$} & difference between initial and final concentrations & 1.65 & 1.62 & 1.39 & 1.31 \\
\hline & methanol extraction & 0.09 & 0.21 & 0.14 & 0.18 \\
\hline
\end{tabular}


Table A3-7 Results of sorption experiments with Z-dimethomorph and TP material.

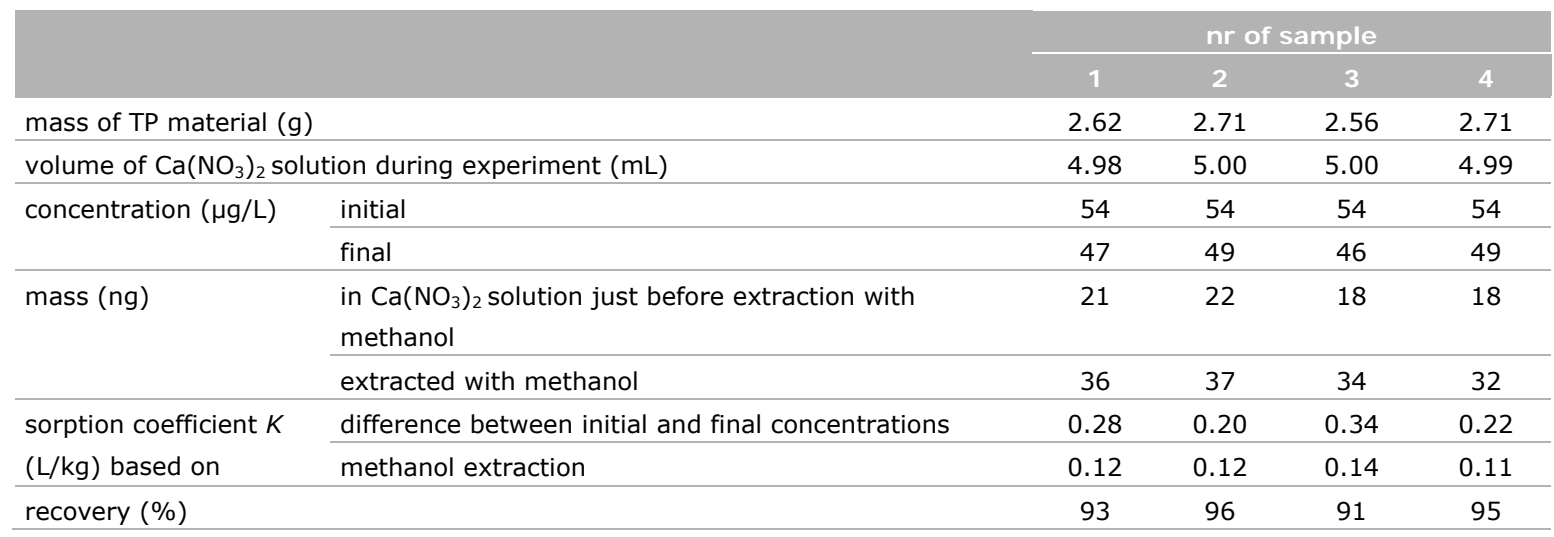

Table A3-8 Results of sorption experiments with Z-dimethomorph and DP material.

\begin{tabular}{|c|c|c|c|c|c|}
\hline & & \multicolumn{4}{|c|}{ nr of sample } \\
\hline & & 1 & 2 & 3 & 4 \\
\hline \multicolumn{2}{|l|}{ mass of DP material $(\mathrm{g})$} & 2.01 & 2.00 & 2.01 & 2.03 \\
\hline \multirow[t]{2}{*}{ concentration $(\mu \mathrm{g} / \mathrm{L})$} & initial & 54 & 54 & 54 & 54 \\
\hline & final & 49 & 47 & 46 & 47 \\
\hline mass (ng) & extracted with methanol & 45 & 50 & 46 & 36 \\
\hline \multirow{2}{*}{$\begin{array}{l}\text { sorption coefficient } K \\
(\mathrm{~L} / \mathrm{kg}) \text { based on }\end{array}$} & difference between initial and final concentrations & 0.28 & 0.38 & 0.45 & 0.37 \\
\hline & methanol extraction & 0.19 & 0.16 & 0.14 & 0.14 \\
\hline
\end{tabular}

Table A3-9 Results of sorption experiments with Z-dimethomorph and SF material.

\begin{tabular}{|c|c|c|c|c|c|}
\hline & & \multicolumn{4}{|c|}{ nr of sample } \\
\hline \multicolumn{2}{|l|}{ mass of SF material $(\mathrm{g})$} & 1.05 & 1.01 & 1.07 & 1.02 \\
\hline \multirow[t]{2}{*}{ concentration $(\mu \mathrm{g} / \mathrm{L})$} & initial & 53 & 53 & 53 & 53 \\
\hline & final & 47 & 45 & 46 & 46 \\
\hline mass (ng) & extracted with methanol & 109 & 91 & 88 & 78 \\
\hline \multirow{2}{*}{$\begin{array}{l}\text { sorption coefficient } K \\
(\mathrm{~L} / \mathrm{kg}) \text { based on }\end{array}$} & difference between initial and final concentrations & 1.01 & 1.37 & 1.16 & 1.26 \\
\hline & methanol extraction & 0.13 & 0.51 & 0.28 & 0.31 \\
\hline
\end{tabular}




\section{Annex 4 Schematic representation of the circulation systems of the mats with the plants}

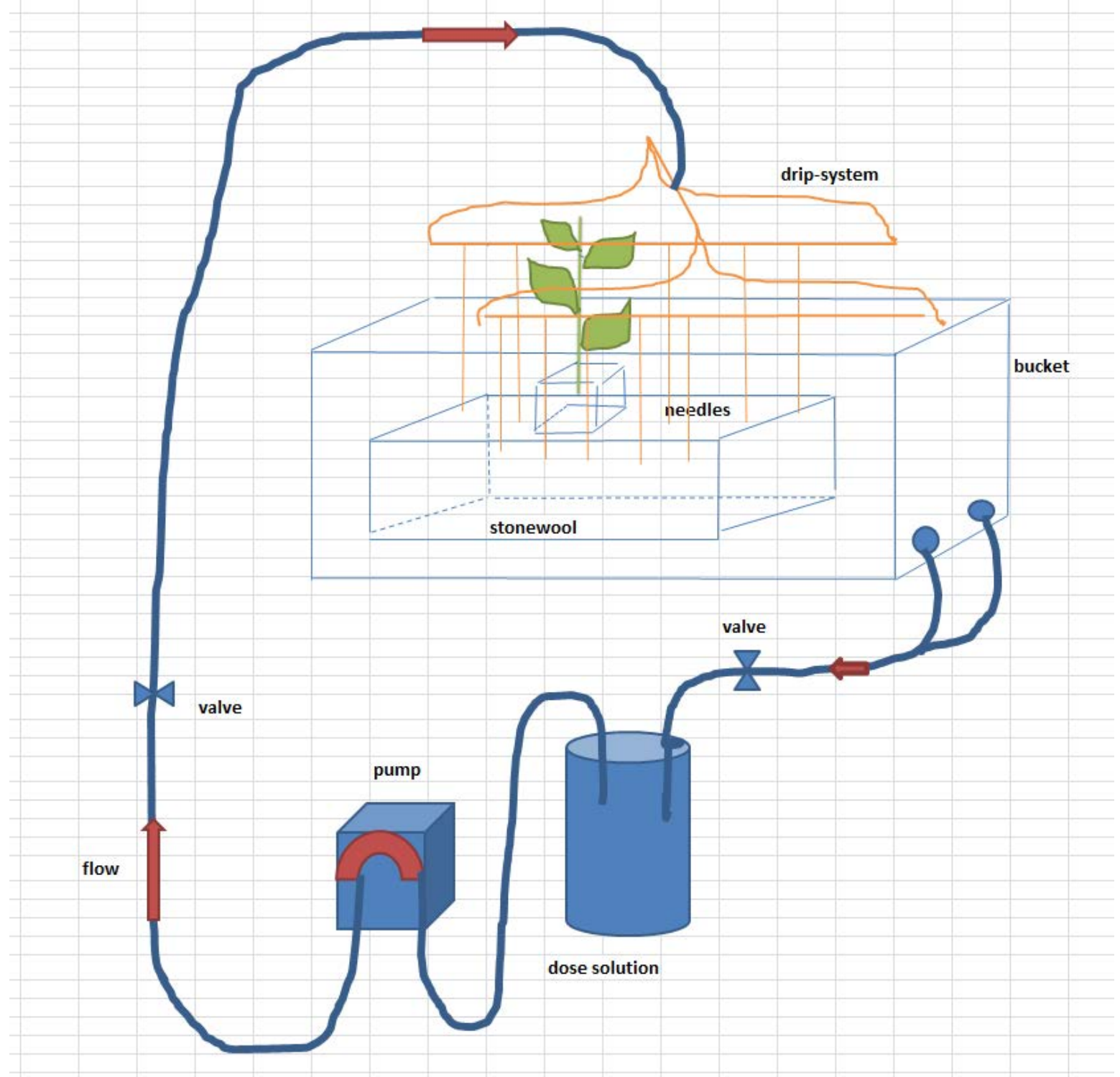


Wageningen Environmental Research P.O. Box 47

6700 AA Wageningen

The Netherlands

T +31 (0)317480700

www.wur.nl/environmental-research

Wageningen Environmental Research Report 2841

ISSN 1566-7197
The mission of Wageningen University and Research is "To explore the potential of nature to improve the quality of life". Under the banner Wageningen University \& Research, Wageningen University and the specialised research institutes of the Wageningen Research Foundation have joined forces in contributing to finding solutions to important questions in the domain of healthy food and living environment. With its roughly 30 branches, 5,000 employees and 10,000 students, Wageningen University \& Research is one of the leading organisations in its domain. The unique Wageningen approach lies in its integrated approach to issues and the collaboration between different disciplines.

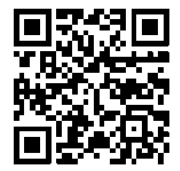





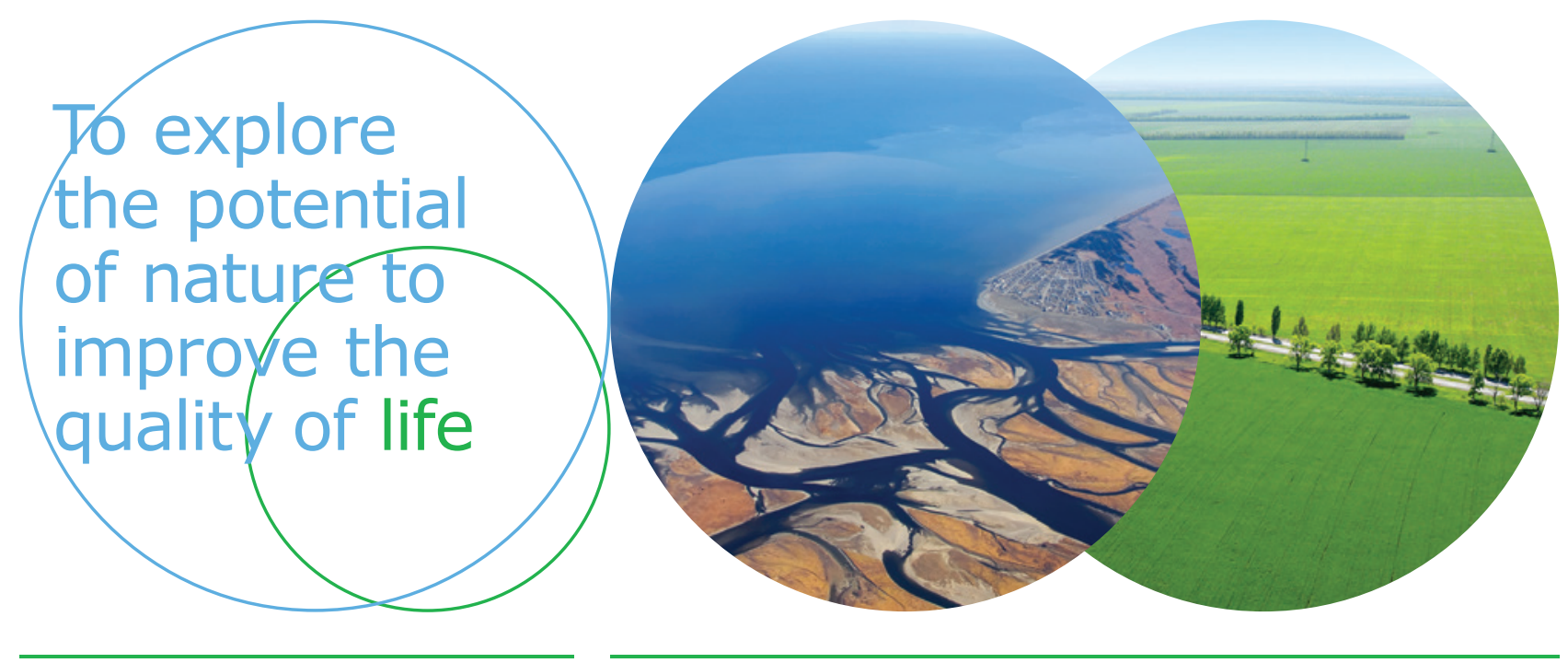

Wageningen Environmental Research P.O. Box 47

$6700 \mathrm{AB}$ Wageningen

The Netherlands

$\mathrm{T}+31(0) 317480700$

www.wur.eu/environmental-research

Report 2841

ISSN 1566-7197
The mission of Wageningen University and Research is "To explore the potential of nature to improve the quality of life". Under the banner Wageningen University \& Research, Wageningen University and the specialised research institutes of the Wageningen Research Foundation have joined forces in contributing to inding solutions to important questions in the domain of healthy food and living environment. With its roughly 30 branches, 5,000 employees and 10,000 students, Wageningen University \& Research is one of the leading organisations in its domain. The unique Wageningen approach lies in its integrated approach to issues and the collaboration between different disciplines. 